\title{
Induction of $\mathrm{NAD}(\mathrm{P}) \mathrm{H}$ :quinone oxidoreductase 1 (NQO1) by Glycyrrhiza species used for women's health: differential effects of the Michael acceptors isoliquiritigenin and licochalcone A
}

\author{
Atieh Hajirahimkhan, Charlotte Simmler, Huali Dong, Daniel D. Lantvit, Guannan Li, Shao- \\ Nong Chen, Dejan Nikolić, Guido F. Pauli, Richard B. van Breemen, Birgit M. Dietz, and \\ Judy L. Bolton ${ }^{*}$ \\ UIC/NIH Center for Botanical Dietary Supplements Research, Department of Medicinal Chemistry \\ and Pharmacognosy, College of Pharmacy, University of Illinois at Chicago, $833 \mathrm{~S}$. Wood Street \\ M/C 781, Chicago, Illinois, 60612-7231
}

\section{Abstract}

For the alleviation of menopausal symptoms, women frequently turn to botanical dietary supplements, such as licorice and hops. In addition to estrogenic properties, these botanicals could also have chemopreventive effects. We have previously shown that hops and its Michael acceptor xanthohumol $(\mathrm{XH})$ induced the chemoprevention enzyme, $\mathrm{NAD}(\mathrm{P}) \mathrm{H}$ :quinone oxidoreductase 1 (NQO1), in vitro and in vivo. Licorice species could also induce NQO1, as they contain the Michael acceptors isoliquiritigenin (LigC) found in Glycyrrhiza glabra (GG), G. uralensis (GU), and $G$. inflata (GI) and licochalcone A (LicA) which is only found in GI. These licorice species and hops induced NQO1 activity in murine hepatoma (Hepa1c1c7) cells; hops >> GI > GG $\approx$ GU. Similar to the known chemopreventive compounds curcumin (turmeric), sulforaphane (broccoli), and $\mathrm{XH}, \mathrm{LigC}$ and LicA were active dose-dependently; sulforaphane $>\mathrm{XH}>\operatorname{LigC}>\operatorname{LicA} \approx$ curcumin $>$ LigF. Induction of the antioxidant response element-luciferase in human hepatoma (Hep-G2-ARE-C8) cells suggested involvement of the Keap1-Nrf2 pathway. GG, GU, and LigC also induced NQO1 in non-tumorigenic breast epithelial MCF-10A cells. In female SpragueDawley rats treated with GG and GU, LigC and LigF were detected in the liver and mammary gland. GG weakly enhanced NQO1 activity in the mammary tissue but not in the liver. Treatment with LigC alone did not induce NQO1 in vivo most likely due to its conversion to LigF, extensive metabolism, and its low bioavailability in vivo. These data show the chemopreventive potential of

\footnotetext{
*Corresponding author: Judy L. Bolton, Ph.D., Department of Medicinal Chemistry and Pharmacognosy, University of Illinois at Chicago, 833 S. Wood Street, M/C 781, Chicago, IL, 60612-7231, ; Email: Judy.Bolton@uic.edu, Phone: 312-996-5280, Fax: 312-996-7107

Supporting Information

UHPLC chromatograms of the EtOH/isopropanol/water extracts and $\mathrm{MeOH}$ extracts of GG, GU, and GI used in vivo and in vitro; Linear regression analysis of NQO1 induction results in Hepa1c1c7 cells treated with licorice extracts GG, GU, and GI as well as hops; linear regression analysis of $\mathrm{NQO} 1$ induction results in Hepa1c1c7 cells treated with LigC, LigF, LicA from licorice, $\mathrm{XH}$ from hops, sulforaphane from broccoli, curcumin from turmeric, and 4'-bromoflavone; crystal violet staining cell viability results of Hepa1c1c7 cells treated with licorice compounds, $\mathrm{LigC}, \mathrm{LigF}$, and LicA, XH from hops, sulforaphane from broccoli, and curcumin from turmeric after $48 \mathrm{~h}$; linear regression analysis of ARE-luciferase induction results in HepG2-ARE-C8 cells treated with licorice extracts GG, GU, and GI as well as hops; linear regression analysis of ARE-luciferase induction results in HepG2-ARE-C8 cells treated with $\mathrm{LigC}$, LigF, LicA from licorice, $\mathrm{XH}$ from hops, sulforaphane from broccoli, and curcumin from turmeric, respectively; SRMMS/MS responses obtained from the analysis of GU extract and the serum, liver, and mammary homogenates of female SpragueDawley rats treated with GU (1.3 g/kg BW per day) for 4 days by gavage are available in Supporting Information. This information is available free of charge via the Internet at http://pubs.acs.org/.
} 
licorice species in vitro could be due to $\mathrm{LigC}$ and LicA and emphasize the importance of chemical and biological standardization of botanicals used as dietary supplements. Although the in vivo effects in the rat model after four day treatment are minimal, it must be emphasized that menopausal women take these supplements for extended periods of time and long-term beneficial effects are quite possible.

\section{Keywords}

Detoxification enzymes; chemoprevention; hops; isoliquiritigenin; licorice; liquiritigenin; menopause; $\mathrm{NAD}(\mathrm{P}) \mathrm{H}:$ quinone oxidoreductase 1

\section{Introduction}

Due to the cancer risk associated with hormone therapy (HT), menopausal women often use botanical dietary supplements such as hops strobiles (Humulus lupulus, Cannabaceae) and licorice roots (Glycyrrhiza species, Fabaceae) as "natural alternatives" primarily for the alleviation of menopausal symptoms. ${ }^{1}, 2$ Despite the controversy on the efficacy of these botanicals for menopausal discomfort, ${ }^{3}, 4$ they remain popular since they are natural, have a long history in traditional medicine, and are therefore perceived as safe. ${ }^{4}$ Menopausal women are more susceptible than younger women to the development of cancers including breast cancer. ${ }^{5}, 6$ They are also frequent and long time consumers of botanicals. Therefore, understanding the chemopreventive potential of women's health botanicals such as licorice would be particularly beneficial for menopausal women.

One strategy for chemoprevention involves induction of detoxification enzymes, such as $\mathrm{NAD}(\mathrm{P}) \mathrm{H}$ :quinone oxidoreductase 1 (NQO1), which play a role in preventing diseases such as cancer, cardiovascular problems, and neurological disorders. ${ }^{7}, 8$ We have previously shown that a specialized exract from the strobiles of hops has chemopreventive effects. ${ }^{9}$ The hops extract and its major Michael acceptor, xanthohumol (XH, Figure 1A) induce detoxification enzymes in hepatoma cells and in rat liver likely through modification of cysteine residues of Keap1 and activation of Nrf2 signaling. ${ }^{9}, 10$ This effect has been previously reported with other naturally occurring electrophilic compounds such as curcumin from turmeric and sulforaphane from broccoli (Figure 1A). ${ }^{11_{-} 19}$

Licorice has more than 30 different species and is a very popular botanical in traditional medicine for various conditions such as digestive problems and wound healing. ${ }^{20}, 21$ It is also commonly used as a natural sweetener in the food industry and as a flavoring agent in toothpastes and cigarettes. ${ }^{22}$ Licorice species are also frequently found as components of popular menopausal formulations. The United States Pharmacopeia recognizes only two species Glycyrrhiza glabra (GG) and G. uralensis (GU) as source of licorice botanicals and the European Medicines Agency also considers Glycyrrhiza inflata(GI) being a legitimate source plant with medicinal properties. ${ }^{23}$ Despite the similarities observed in the morphology of the roots of these Glycyrrhiza species, they are known to exhibit marked chemical differences, which have been shown to ultimately lead to variation in their biological activities. ${ }^{23-26}$ However, these significant differences have mostly been overlooked in botanical research and in the dietary supplement marketplace. ${ }^{27}, 28$ Besides 
glycyrrhizin, a triterpene saponin responsible for the sweet taste of licorice, the major constituents found in all three Glycyrrhiza species are glycosides of the flavanone liquiritigenin (LigF) and its chalcone isomer isoliquiritigenin (LigC, Figure 1B) ${ }^{25}, 29 \mathrm{We}$ have recently shown that $\mathrm{LigC}$ and $\mathrm{LigF}$ are interconvertible under physiological conditions influencing their biological responses profoundly. ${ }^{25}, 30$ Similar to the chalcone XH from hops, $\mathrm{LigC}$ is a Michael acceptor with the potential to covalently modify cellular proteins resulting in modulation of biological pathways. ${ }^{18}, 19,31 \mathrm{LigF}$ is an estrogenic compound with a higher tendency to interact with estrogen receptor beta (ER $\beta)$ than with ERa. ${ }^{25,32,33}$ Licochalcone A ( LicA) which is specific to GI also contains an $\alpha, \beta$-unsaturated carbonyl and is an electrophilic Michael acceptor (Figure 1B). ${ }^{23}, 28$ Different chemopreventive properties have been described for LicA such as the inhibition of carcinogenic oxidative estrogen metabolism through inhibition of arylhydrocarbon receptor (AhR) pathways. ${ }^{26}$

The aim of the present study was to systematically analyze the in vitro and in vivo NQO1 induction potential of the three medicinally used Glycyrrhiza species that have been DNA authenticated and chemically well characterized and to highlight any differences between extracts and the selected bioactive constituents. ${ }^{23}$ Due to the similarities between the classes of compounds in licorice and hops, a comparative analysis was performed. Our findings emphasize on the importance of the simultaneous chemical/biological characterization of licorice botanicals used for women's health.

\section{Materials and Methods}

\section{Chemicals and materials}

All chemicals and reagents were purchased from Sigma-Aldrich (St. Louis, MO), unless otherwise indicated. All media for cell culture were purchased from Invitrogen (Grand Island, NY). Fetal bovine serum (FBS) was purchased from Atlanta Biologicals (Norcross, $\mathrm{GA})$. Isoliquiritigenin $(\mathrm{LigC})$ and Liquiritigenin $(\mathrm{LigF})$ were acquired from ChromaDex (Irvine, CA). Licochalcone A (LicA), glabridin, 7-hydroxyflavone, and 18 $\beta$-glycyrrhetinic acid were purchased from Sigma-Aldrich (St. Louis, MO). Liquiritin, isoliquiritin, liquiritin apioside, isoliquiritigenin apioside and licuraside were isolated from licorice extract. ${ }^{34} \mathrm{XH}$ was isolated from $H$. lupulus as described previously. ${ }^{35}$ Sulforaphane was obtained from Cayman Chemical (Ann Arbor, MI). Curcumin was purchased from Fluka and 4'bromoflavone (BF) from Santa Cruz Biotechnology (Dallas, TX). LC-MS-grade acetonitrile and methanol were purchased from Thermo Fisher (Fair Lawn, NJ).

\section{Preparation and characterization of plant extracts}

The hops (Humulus lupulus) extract (HHEO2 containing \%5.4 XH) used in this study was an ethanol extract of spent hops after supercritical $\mathrm{CO}_{2}$ extraction of pelletized strobiles of hops obtained from Hopsteiner (Mainburg, Germany/New York) as described previously. ${ }^{36}$ The extracts of licorice (G. glabra L., G. uralensis Fisch. ex DC., and G. inflata Batalin) used in the in vitro assays were the chemically characterized methanol extracts of the respective dried DNA authenticated licorice root powders, as described previously. ${ }^{23}, 25-{ }^{27}$ For in vivo studies, powdered roots from Glycyrrhiza species were extracted by maceration at room temperature with a solvent mixture composed of ethanol (200 USP proof), isopropranol, and 
water (90:5:5, v/v) and a plant powder/volume of solvent ratio of 1/15. This extraction procedure optimized the yield concentration of bioactive phenolic constituents, while reducing the extraction of primary metabolites and glycyrrhizin. The chemical equivalence between the in vivo and in vitro extracts was checked through a combination of Ultra High Pressure Liquid Chromatography (UHPLC) coupled with a photo-diode array (PDA) detector and qHNMR analyses in order to obtain characteristic chemical fingerprints and determine the concentration of bioactive compounds (Figure S4). ${ }^{23}, 34,37$ The marker compounds glabridin and LicA, as well as LigF, LigC, and their glycosides (liquiritin, liquiritigenin 7- $O$-apiosylglucoside, liquiritin apioside, isoliquiritin, isoliquiritin apioside and licuraside) in addition to glycyrrhizin were quantified in each Glycyrrhiza extract by UHPLC as described previously. ${ }^{23}$ The areas under the curve (AUC) were taken at $360 \mathrm{~nm}$ for all chalcones, at $275 \mathrm{~nm}$ for all flavanones and at $254 \mathrm{~nm}$ for glycyrrhizin. Each Glycyrrhiza extract was examined in duplicate. Quantitative results obtained for each LigF glycoside were corrected by a factor corresponding to $23 /[\mathrm{MW}$ of LigF glycoside], thereby leading to their concentration as LigF equivalents. The same methodology was applied for the quantitative results obtained for each $\mathrm{LigC}$ glycoside.

\section{Purity determination of licorice and hops constituents}

The purity of each investigated compound was determined by quantitative $1 \mathrm{D}{ }^{1} \mathrm{H}$ NMR using the $100 \%$ method $^{38}$ and yielded the following purity percentages (in $\% \mathrm{w} / \mathrm{w}$ ): LicA 96.1\% (ratio trans/cis = 93/7), $\mathrm{LigF} 96.6 \%, \mathrm{LigC} 98.6 \%$, glabridin 99.4\%, 8-PN 95.0\%, and XH $96.5 \%$.

\section{Cell culture conditions}

Non-tumorigenic breast epithelial MCF-10A cells were obtained from American Type Culture Collection (ATCC) and maintained in DMEM/F12 supplemented with 5\% fetal bovine serum (Atlanta Biologicals, Atlanta, GA), $0.002 \%$ epidermal growth factor (Life Technologies, Grand Island, NY), $0.01 \%$ Cholera toxin, $0.005 \%$ hydrocortisone, $0.1 \%$ insulin, $1 \%$ penicillin-streptomycin and incubated in $5 \% \mathrm{CO}_{2}$ at $37^{\circ} \mathrm{C}$. Hepa $1 \mathrm{c} 1 \mathrm{c} 7$ murine hepatoma cells were supplied by Dr. J. P. Withlock, Jr. (Stanford University, Stanford, CA). Cells were maintained in a-minimum essential medium (MEME) supplemented with $1 \%$ penicillin-streptomycin and 10\% fetal bovine serum. HepG2 cells stably transfected with antioxidant response element (ARE) luciferase reporter (HepG2-ARE-C8) were kindly provided by Dr. A. N. Tony Kong (Rutgers University, Piscataway, NJ). Cells were grown in DMEM/F12 supplemented with $10 \%$ FBS, $1 \%$ penicillin-streptomycin, $1 \%$ geneticin, and $0.06 \%$ insulin.

\section{NQO1 activity}

Murine hepatoma Hepa1c1c7 cells, an established model for the assessment of NQO1 activity, were treated with the licorice extracts, the selected pure constituents, hops extract, and $\mathrm{XH}$, and the change in NQO1 activity was evaluated as described previously. ${ }^{39}$ Activities were expressed as $\mathrm{CD}$ values, referring to the concentration of an agent required to double the activity of NQO1. Chemopreventive indices (CI values) were calculated as the ratio of toxicity $\left(\mathrm{IC}_{50}\right)$ versus the $\mathrm{CD}$ value. ${ }^{40}$ 


\section{ARE luciferase activity}

Human hepatoma Hep-G2-ARE-C8 cells stably transfected with ARE were treated with the licorice extracts, the selected pure constituents, the hops extract, $\mathrm{XH}$, curcumin, and sulforaphane. The induction of ARE-luciferase was evaluated after $24 \mathrm{~h}$ using the single luciferase kit (Promega, Madison, WI) as described previously. ${ }^{9}, 41$ The results were normalized to the protein concentration evaluated using the BCA assay kit.

\section{Western blotting}

Non-tumorigenic breast epithelial MCF-10A cells were treated with the licorice extracts, the selected pure constituents, hops extract, and XH. Protein expression of NQO1 was evaluated using western blot as described previously. ${ }^{36}$ Anti NQO1 and anti $\beta$-actin were used as primary antibodies. Antibodies were diluted in blocking solution (5\% BSA in TBS with $0.1 \%$ tween 20). Blots were incubated with primary antibodies overnight at $4^{\circ} \mathrm{C}$ while shaking and upon addition of the appropriate secondary antibody for $1 \mathrm{~h}$ at room temperature. Imaging and quantitative densitometric analysis of the blots were performed using luminescence substrate (Thermo Scientific, Waltham, MA) and FluroChem software (Cell Biosciences, Santa Clara, CA). Each protein density band was normalized to its corresponding $\beta$-actin band density and reported relative to protein expression. The data represents three independent experiments and is stated as mean $\pm \mathrm{SD}$.

\section{Animal treatment}

Female Sprague-Dawley rats were received at 7 weeks of age from Harlan (Indianapolis, IN). All rats consumed powdered Harlan/Teklad purified diet (Indianapolis, IN). After one week of acclimation, animals were divided into six groups based on their weight ( $\mathrm{n}=5 /$ group) : (i) control diet plus vehicle control (corn oil $/ 50 \%$ polyethylene glycol) by gavage; (ii) experimental diet containing 4'-bromoflavone ( $150 \mathrm{mg} / \mathrm{kg}$ BW per day) plus vehicle control by gavage; (iii) control diet plus GU extract ( $1.3 \mathrm{~g} / \mathrm{kg}$ BW per day) by gavage; (iv) control diet plus GG extract (1.3 g/kg BW per day) by gavage; (v) control diet plus LigF (80 $\mathrm{mg} / \mathrm{kg}$ BW per day) by gavage; (vi) control diet plus LigC (40 mg/kg BW per day) by gavage. The recommended human clinical dose of licorice supplements was considered as a basis for calculation of the lower dose for rats and then 20X higher concentration $(1.3 \mathrm{~g} / \mathrm{kg}$ BW per day) was administered to evaluate the potential pharmacological effect. The doses of $\mathrm{LigF}$ and $\mathrm{LigC}$ were equivalent to their contents (considering all quantified glycosides of $\mathrm{LigF}$ and $\mathrm{LigC}$ ) in the administered GG extracts. The animals were treated for 4 days. All animals and their food were weighted daily. No difference in food intake was observed between treatment groups. On day 4 , animals were sacrificed by $\mathrm{CO}_{2}$ asphyxiation, and serum and tissues were collected, snap frozen, and stored at $-80{ }^{\circ} \mathrm{C}$ for later analysis. The animal protocol complied with the Guide for the Care and Use of Laboratory Animals and all procedures were approved by UIC's Institutional Animal Care and Use Committee (Protocol No. 08-101).

\section{UHPLC-MS/MS analysis of LigF and LigC in licorice extracts, rat serum, and tissues}

The licorice extracts were dissolved in 50\% aqueous methanol at $20 \mu \mathrm{g} / \mathrm{mL}$. Rat serum (100 $\mu \mathrm{L}$ ) was mixed with $400 \mu \mathrm{L}$ acetonitrile containing $10 \mathrm{ng} / \mathrm{mL}$ 7-hydroxyflavone as internal 
standard. Tissues (300-900 mg) were weighed and homogenized in $3 \mathrm{~mL} 70 \%$ aqueous methanol. A $200 \mu \mathrm{L}$ aliquot of each homogenate was mixed with $800 \mu \mathrm{L}$ acetonitrile containing $5 \mathrm{ng} / \mathrm{mL}$ 7-hydroxyflavone. Serum/tissue homogenate mixtures were vortexed and then centrifuged for $15 \mathrm{~min}$ at $12,000 \times g$ at $4{ }^{\circ} \mathrm{C}$. The supernatant was evaporated to dryness and reconstituted with $50 \mu \mathrm{L}$ of $50 \%$ aqueous methanol. A $5 \mu \mathrm{L}$ aliquot of each serum/tissue extract and a $2 \mu \mathrm{L}$ aliquot of each licorice extract was analyzed using UHPLCMS/MS. Calibration curves were prepared by spiking blank serum/tissue homogenate with known concentrations of the reference standards $(0.5-1000 \mathrm{ng} / \mathrm{mL})$.

UHPLC-MS/MS analyses were carried out using a Shimadzu (Kyoto, Japan) LC/MS-8050 triple quadrupole mass spectrometer equipped with a Shimadzu Nexera UHPLC system. Analytes were separated on a Waters (Milford, MA) Acquity UPLC BEH C $18.1 \times 100 \mathrm{~mm}$ column (1.7 $\mu \mathrm{m}$ particle size). For quantitative analysis, the gradient was: $1-3.5 \mathrm{~min}$, from $15-35 \%$ B, $3.5-5.5 \mathrm{~min}$, from $35-95 \% \mathrm{~B}$, hold at $95 \%$ B for $1 \mathrm{~min}$. For the qualitative analysis of licorice extracts, the gradient was: $0.5-14.5 \mathrm{~min}$, from $12-80 \%$ B. (A: $0.1 \%$ formic acid in water, B: acetonitrile) at a flow rate of $0.6 \mathrm{~mL} / \mathrm{min}$. The data were acquired using selected reaction monitoring (SRM) in electrospray mode with polarity switching and the following SRM transitions: $m / z 417$ - 255 (liquiritin, isoliquiritin), $m / z 549$ - 255 (liquiritin apioside, isoliquiritin apioside, licuraside), $m / z 255$-119 (liquiritigenin, isoliquiritigenin), m/z 323 - 201 (glabridin), $m / z 469$ - 425 (glycyrrhetinic acid), m/z 339 121 (licochalcone A), and $\mathrm{m} / \mathrm{z} 237$ - 180 (7-hydroxyflavone, internal standard).

\section{Analysis of NQO1 activity in vivo}

Frozen samples of liver from the treated rats were homogenized using $0.25 \mathrm{M}$ aqueous sucrose and centrifuged at $15000 \times g$ for $1 \mathrm{~h}$ at $4{ }^{\circ} \mathrm{C} .{ }^{42}$ The supernatant was collected and $0.1 \mathrm{M} \mathrm{CaCl}_{2}$ solution added. Samples were incubated for $30 \mathrm{~min}$ at $0{ }^{\circ} \mathrm{C}$ and centrifuged at $15000 \times g$ for $1.5 \mathrm{~h}$ at $4{ }^{\circ} \mathrm{C}$. For mammary glands, the frozen tissue was homogenized in icecold $0.1 \mathrm{M}$ phosphate buffer $(\mathrm{pH} 6.5)$ and centrifuged for $1.5 \mathrm{~h}$ at $15,000 \times g$ at $4{ }^{\circ} \mathrm{C}$. The supernatant was used for NQO1 analysis. Protein concentrations were measured using BCA assay kit, and the samples were diluted accordingly to give $5 \mu \mathrm{g}$ liver protein and $30 \mu \mathrm{g}$ mammary gland protein in $50 \mu \mathrm{L}$ supernatants, respectively. The samples were then tested for NQO1 activity as described previously. ${ }^{42}$

\section{Statistical analysis}

Linear regression analysis. After obtaining the dose-response curves for the induction of NQO1 activity and ARE-luciferase linear regression analysis was performed with GraphPad Prism (version 5.00 for Windows, Graph Pad Software, La Jolla California USA, www.graphpad.com). Linear regression analysis was performed using the concentration ranges not associated with toxicity or saturation of the responses. The slopes of the lines were used as a measure for the inducing potential of the tested materials. Significance. Data are reported as means $\pm \mathrm{SD}$. Significant differences from control values were determined by one-way ANOVA with a follow-up Dunnett test $(\mathrm{P}<0.05)$. 


\section{Results}

\section{(Table 1) UHPLC-UV metabolite profiling and characterization of licorice extracts}

Licorice extracts were analyzed by UHPLC-UV to quantify the bioactive aglycones, $\mathrm{LigF}$ and $\mathrm{LigC}$, as well as their major glycosides, glabridin and LicA. ${ }^{26}$ The UHPLC-UV profiles revealed that both in vivo and in vitro extracts displayed similar chemical profiles (Figure S4, Table 1). LigF and LigC glycosides can be considered as bio-precursors or pro-drugs of their corresponding aglycones since they are likely deglycosylated in vivo as will be discussed later in the tissue analysis results and discussion sections. Deglycosylation can occur throughout the digestive tract, and there are controversies on whether this process can start in the stomach. ${ }^{43}$ Therefore, all quantified glycosides of LigF and LigC were expressed as $\mathrm{LigF}$ and $\mathrm{LigC}$ equivalents (Table 1). ${ }^{26}$ The results presented in Table 1 demonstrated that the extracts from the three Glycyrrhiza species showed characteristic differences in terms of flavanone and chalcone composition. The GI extract had the highest total concentration of chalcones (LicA and $\mathrm{LigC}$ ), whereas the GG and GI extracts had similar amounts of LigC equivalents. GU had the lowest levels of chalcones and therefore the rank order for the chalcone contents of the three Glycyrrhiza species would be GI> GG > GU. As a result, we hypothesized that the relative NQO1 induction could follow the same order and would be GI $>\mathrm{GG}>\mathrm{GU}$.

\section{(Table 2) Licorice species as well as LigC and LicA induce NQO1 activity in murine hepatoma cells}

Murine Hepa1c1c7 cells are a well-established model for evaluating the NQO1 inducing potential of xenobiotics. ${ }^{39}$ The licorice and hops extracts showed a dose-dependent induction of NQO1 in Hepa1c1c7 cells (Figure 2A, Table 2). The induction activity of GI was comparable to that of GG and higher than that of GU (Table 2). The efficacy of GI was better than either GG or GU (Figure 2A). Hops extract was more active than any of the three licorice extracts with a more pronounced toxicity compared to GG and GU (Table 2). The rank order for concentration to double the activity $(\mathrm{CD})$ values is Hops $<<\mathrm{GI} \cong \mathrm{GG}<\mathrm{GU}$ (Table 2). The different NQO1 inducing properties of the extracts can also be illustrated by the slope of the linear regression analysis of the linear part of the dose-response curves revealing a similar rank order of activity as the $\mathrm{CD}$ values: Hops $<<\mathrm{GI}<\mathrm{GG}<\mathrm{GU}$ (Table 2, Figure S2A). The line fit was set to include the concentrations in the linear part of the doseresponse curves, in which toxicity and saturation effects do not play a role (Figure S2A, Table 2).

$\mathrm{LigC}$, the common Michael acceptor chalcone in all three licorice species, showed a dosedependent induction of NQO1 with a significant efficacy (Figure 2B, Table 2). Similarly, the other Michael acceptor, LicA, which is the marker compound of GI, induced NQO1 dosedependently but with lower efficacy (Figure 2B, Table 2). LigF, the estrogenic flavonone in Glycyrrhiza species and the cyclization product of $\mathrm{LigC}$ under physiological conditions, was a weak NQO1 inducer (Figure 2B, Table 2). This observed activity was probably due to conversion to LigC. ${ }^{30}$ Glabridin, the species-specific marker compound of GG did not show induction of NQO1 activity (Figure 2B). XH, the electrophilic chalcone of hops, induced NQO1 at lower concentrations than LigC and LicA (Figure 2B) and was more toxic than 
LigC (Table 2, Figure S3). The known chemopreventive compounds, curcumin from turmeric and sulforaphane from broccoli, were also tested for comparison (Figure 2C, Table

2). ${ }^{44}, 45$ Curcumin induced NQO1 with activity similar to LicA, while sulforaphane exhibited a higher NQO1 induction over a broad concentration range demonstrating the highest activity of all compounds tested (Figure 2C, Table 2). Linear regression analysis confirmed these observations showing a similar rank order of NQO1 activity projected in CD values. Relative to its high NQO1 inducing activity, the toxicity of sulforaphane was low resulting in the highest chemopreventive index $[\mathrm{CI}]^{46}$ (Figure 2D, Table 2). The rank order of CI values was sulforaphane $>>\mathrm{XH}>\operatorname{LigC}>\operatorname{LicA}=$ curcumin (Figure 2D, Table 2).

\section{Licorice species as well as LigC and LicA induce ARE-luciferase in human hepatoma Hep- G2-ARE-C8 cells}

The luciferase gene linked to the ARE element in Hep-G2-ARE-C8 cells is a unique tool to evaluate the capacity of xenobiotics to activate antioxidant responses and to test for the involvement of the Keap1-Nrf2-ARE pathway. ${ }^{47}$ Similar to the NQO1 induction results, all licorice extracts GG, GU, and GI induced ARE luciferase activity dose dependently (Figure 3A). Unlike the NQO1 induction activity assay, the data showed that the activity of GI was significantly higher than hops, GG, and GU (Figure 3A). This observation was reflected in the linear regression analysis of the data (Table 2, Figure 3SA).

The Michael acceptors from licorice, $\mathrm{LigC}$ and LicA, also induced ARE-luciferase activity dose dependently; however, LicA exhibited a higher ARE-luciferase induction level than $\mathrm{LigC}$ in contrast to their NQO1 activities (Figure 3B, Figure 2B). This observation was also reflected in the enhanced slope of LicA compared to that of LigC, suggesting a higher tendency of LicA to activate ARE (Table 2, Figure 3SB). LicA showed toxic effects at concentrations of $\sim 10 \mu \mathrm{M}$ in HepG2-ARE-C8 cells, leading to a decline in ARE-luciferase signal. LigF is not a Michael acceptor and was not active in the ARE-luciferase assay consistent with its low NQO1 induction activity (Figure 2B, Figure 3B). The ARE-luciferase induction of $\mathrm{XH}$ was comparable to that of LicA, with both compounds sharing very similar slopes (Figure 3B, Figure 3SB, Table 2). The ARE-luciferase activities of $\mathrm{XH}$ and curcumin were comparable to their NQO1 inducing activities (Figure 3B). However, while sulforaphane exhibited a higher slope in inducing NQO1 compared to other tested compounds (Figure 2C, Figure S1B, Table 2), its slope in inducing ARE-luciferase was comparable to that of XH and LicA (Figure 3B, Figure S3B, Table 2).

\section{Licorice species and LigC induce NQO1 protein expression in non-tumorigenic breast epithelial MCF-10A cells}

To determine whether the hops and licorice extracts also induce NQO1 in non-tumorigenic breast cells, western blot analysis of NQO1 protein was performed in non-tumorigenic $\mathrm{ER}(-)$ breast epithelial MCF-10A cells. The western blot analysis showed that NQO1 is induced significantly by GG and GU extracts at $10 \mu \mathrm{g} / \mathrm{mL}$ in MCF-10A cells after $24 \mathrm{~h}$ (Figure 4A). Hops extract exhibited a higher induction level at $5 \mu \mathrm{g} / \mathrm{mL}$ (Figure 4A). The Michael acceptors from licorice, $\operatorname{LigC}$ and LicA, also induced NQO1 at $5 \mu \mathrm{M}$; however, the effect caused by LicA was not statistically significant (Figure 4B). XH from hops had much stronger activity at the same concentration (Figure 4B). These data suggested that licorice 
extracts and the tested constituents might increase NQO1 protein levels in normal breast cells. In order to confirm the in vitro effects described above, animal models were employed subsequently.

\section{LigC and LigF are better absorbed when administered through the licorice extracts, and reach the target tissue mammary gland}

As described in the Materials and Methods section, female mature Sprague-Dawley rats were randomly distributed in groups of 5 and treated orally every $24 \mathrm{~h}$ for four days. The LC-MS/MS analysis of GG and GU extracts, used in the in vivo study, showed the presence of free $\mathrm{LigC}$ and $\mathrm{LigF}$ as well as their different glycosylated forms in the extracts (Figure 5A, Figure S5). It also showed the presence of glabridin (a marker compound of GG) in GG extract (Figure 5A). In the animals treated with GG or GU extracts, only trace amounts of unconjugated $\mathrm{LigC}$ and $\mathrm{LigF}$ were detected in the serum (below limit of quantitation, $<0.5$ $\mathrm{ng} / \mathrm{mL}$ ) (Figure 5A, Figure S5). However, tissue analysis of the animals treated with the extracts showed quantifiable amounts of free $\mathrm{LigF}(2-10 \mathrm{ng} / \mathrm{g}$ tissue) in both liver and mammary tissue homogenates (Figure 5A, Figure S5). For LigC (Figure 5B) and LigF (data not shown) administered alone to animals, free $\mathrm{LigC}$ and $\mathrm{LigF}$ were detected in the serum $(<0.5 \mathrm{ng} / \mathrm{mL})$. Free LigF (10-20 ng/g tissue) was measured in the tissues of LigF-treated animals, but less than $1 \mathrm{ng} / \mathrm{g}$ tissue of $\mathrm{LigF}$ and LigC were detected in LigC-treated animals. An enrichment of estrogenic LigF was observed in mammary tissue in all treatment groups including the LigC treated animals. In all groups of animals, $\mathrm{LigC}$ and $\mathrm{LigF}$ were observed as aglycones and glucuronides (data not shown). After enzymatic deconjugation of serum samples obtained $24 \mathrm{~h}$ after the last dose, quantitation of $\operatorname{LigC}$ in the hydrolyzed serum showed the highest levels of LigC in animals treated with GG $(10.28 \mathrm{ng} / \mathrm{mL})$ compared with those treated with equivalent amount of $\operatorname{LigC}(<0.5 \mathrm{ng} / \mathrm{mL}$, data not shown $)$.

\section{NQ01 activity increased in the mammary glands of the animals treated with GG extract}

Induction of NQO1 in the rat liver homogenates after treatment with the positive control, 4'bromoflavone, was significant relative to vehicle treatment, which was consistent with previous reports. ${ }^{9}, 48$ While GG extract did not change the NQO1 activity in the liver (Figure 6A), it induced NQO1 in mammary glands significantly (Figure 6B). GU extract and pure LigC did not change NQO1 activity in either of the tissues (Figure 6A, Figure 6B). LigF reduced NQO1 activity in the liver significantly (Figure 6A), but did not change NQO1 levels in mammary tissue (Figure 6B).

\section{Discussion}

Previous studies have reported cytoprotective effects by licorice and by some of its constituents such as LigC and LicA. ${ }^{26}, 31,49-51$ For example, the extracts and bioactive compounds have been reported to induce chemopreventive responses through activation of apoptotic pathways, anti-inflammatory effects, and inhibition of oxidative estrogen metabolism. ${ }^{26}, 49,51-53$ It has also been shown that GU induces Nrf2-mediated genes in hepatoma cells and animal tissues. ${ }^{50} \mathrm{LigC}$ was also reported to activate NQO1 in vitro and in vivo; however, it failed to retard breast tumor growth in animal models which might be associated with its conversion to the estrogenic compound LigF under physiological 
conditions as well as its poor bioavailability when administered alone, as suggested by the results presented herein. ${ }^{25}, 30,31,42$

The fact that licorice has more than 30 different species with various chemical profiles and thus distinct biological activities has often been neglected. ${ }^{26}, 27,54$ The majority of previous biological evaluations of licorice have been performed with GG, which is the most commercialized species in the western world, and with GU, which is more popular in Asian countries. Comparatively, the biological properties of GI extracts have not been extensively investigated. More importantly, up to now, studies simultaneously comparing the chemical profiles and biological properties of these three medicinal Glycyrrhiza species are rare. ${ }^{25}, 26$ Nevertheless, these comparative analyses are fundamental for the meaningful interpretation of the biological results and adequate chemical standardization of licorice botanical dietary supplements.

The dose-dependent induction of NQO1 activity in Hepa1c1c7 cells by extracts from the three different Glycyrrhiza species (Figure 2A, Table 2) was consistent with the differences in their chemical profiles (Table 1). GI contains more of the electrophilic chalcones that could potentially lead to better induction of NQO1 (Figure 2A). However, its CD value and slope of the NQO1 induction dose-response curve were only slightly better compared to GG. Both licorice chalcones, $\mathrm{LigC}$ and LicA, induced NQO1; however, LigC was more effective than LicA. The intensity of NQO1 activity observed with GG and GI as well as LigC and LicA might be explained by the mechanistic differences between the active chalcones as will be further discussed. The higher NQO1 activity and the enhanced slope of hops extract in comparison to the three licorice extracts (Figure 2A, Table 2, Figure S1A) could be due to the increased stability of $\mathrm{XH}$ in hops as compared to LigC in licorice which easily converts to LigF under physiological conditions (Figure 1B, Figure 5B). ${ }^{30}$

The mechanism of induction of detoxification enzymes such as NQO1 is believed to proceed through interaction of the transcription factor Nrf2 with the antioxidant response elements (AREs) in the promoter of their genes (Scheme 1). ${ }^{55} 58$ Under normal conditions, Nrf2 is sequestered in the cytosol by a cysteine-rich sensory protein, Keap1, which targets Nrf2 for ubiquitination and degradation. However, electrophilic compounds such as the chalcones in this study as well as reactive oxygen species (ROS) can interact with sulfhydryl groups in Keap1 and change the conformation of the protein (Scheme 1). ${ }^{59}, 60$ This will result in the inability of Keap1 to target Nrf2 for degradation resulting in its accumulation in the nucleus and its enhanced interaction with ARE. This will ultimately lead to higher levels of detoxification enzymes such as NQO1, which contribute to the inactivation and excretion of reactive oxidative metabolites and therefore to cytoprotection (Scheme 1). ${ }^{61}, 62$ It has also been shown that xenobiotic response elements (XRE) that are regulated by the AhR are present in the promoter region of NQO1 and other Nrf2 genes in close proximity to ARE elements. ${ }^{56,63}$ The licorice Michael acceptors in this study, have been shown to modulate the AhR pathway ${ }^{26}$ and might ultimately influence the induction of NQO1 (Scheme 1); however, the detailed mechanistic events leading to the cross talk between AhR and Nrf2 in influencing NQO1 induction are not well understood. ${ }^{63} 65$ 
All three Michael acceptors, $\mathrm{XH}, \mathrm{LigC}$, and LicA significantly induced ARE-reporter activity suggesting activation of the Keap1-Nrf2 pathway (Figure 3B, Table 2, Figure S3B). Interestingly, the level of induction by LicA was much higher than that of $\mathrm{LigC}$ and comparable to sulforaphane and $\mathrm{XH}$ in the ARE-luciferase induction assay; however, the induction of NQO1 by LicA was significantly lower (Figure 3B, Figure 2B, Table 2, Figure S1B, Figure S3B). Recently, it was shown that LicA is an antagonist of AhR, inhibits XRE activity, and blocks carcinogenic oxidative estrogen metabolism. ${ }^{26}$ Therefore, LicA might activate AREs at the promoter of NQO1 while simultaneously inhibiting the proximal XREs at this region, resulting in a lower NQO1 induction (Figure 2, Scheme 1). LigC, on the other hand, was not shown to inhibit XRE, and it promoted carcinogenic oxidative estrogen metabolism. ${ }^{26}$ Other studies demonstrated that $\mathrm{LigC}$ and $\mathrm{XH}$ mainly induce NQO1 through ARE, but not through XRE. ${ }^{31}, 66$ These data suggested that similar to hops and XH, the licorice extracts, $\mathrm{LigC}$, and LicA induced NQO1 through Keap1-Nrf2 pathway; however, LicA and thus GI might modulate Nrf2-mediated detoxification genes through XRE and ARE, simultaneously (Scheme 1). ${ }^{60}, 63$ The weak NQO1 induction by LigF could be related to its conversion to $\mathrm{LigC}$ after $48 \mathrm{~h}$ (Figure $2 \mathrm{~B}$ ). ${ }^{30}$

To compare the NQO1 inducing properties of licorice compounds with other well known chemopreventive compounds, curcumin and sulforaphane were analyzed in parallel. While sulforaphane exhibited very good NQO1 inducing properties (Figure 2C) and the best CI value (Figure 2D, Figure S1B, Table 2) compared to the other tested compounds, its AREluciferase inducing activity was comparable to $\mathrm{XH}$ and LicA (Figure 3B, Figure S3B, Table 2). This observation suggests that sulforaphane-induced NQO1 through ARE and other parallel mechanisms as previously reported. ${ }^{16}, 46$ Nevertheless, apart from the mechanistic diversity between the tested compounds, the varied responsiveness of different cell lines (Hepa1c1c7 versus HepG2-ARE-C8) to certain compounds might contribute to the differences observed between NQO1 induction and ARE-luciferase data. Additionally, varied reactivities of the Michael acceptors towards certain proteins might contribute to the observed differences. While sulforaphane is effective for chemoprevention, it is not associated with menopausal symptom relief. In contrast, licorice and its active compounds are directly relevant to the relief of menopausal symptoms ${ }^{4}, 67,68$ and the in vitro observed detoxification enzyme inducing effects as well as literature reports might suggest further benefit. ${ }^{42}, 50$ As the in vivo detoxification enzyme inducing effects of licorice in this shortterm rat model are minimal, long-term efficacy studies are necessary to analyze whether licorice has chemopreventive effects in vivo.

As the major goal of the study was to understand the chemopreventive potential of licorice in breast tissue, MCF-10A cells were employed as a model to evaluate the NQO1 induction by the three major Glycyrrhiza species and their bioactive constituents in non-tumorigenic breast epithelial cells. The significant induction of $\mathrm{NQO} 1$ by GG, GU, and LigC in MCF-10A cells (Figure 4) further confirmed the chemopreventive potential of these licorice species and LigC. It has been shown that sulforaphane reduced estrogen DNA adducts in MCF-10A cells through up-regulating enzymes that detoxify genotoxic estrogen quinones, such as NQO1. ${ }^{69}$ Similarly, we have recently shown that LicA significantly inhibits estrogen metabolism to genotoxic catechols in MCF-10A cells. ${ }^{26}$ 
Intact, mature, female Sprague-Dawley rats were employed to study the role of licorice extracts and their characteristic aglycones LigC and LigF in modulating NQO1 activity in vivo. As GI is not recognized by the United States Pharmacopoeia and obtaining pure plant material of this single species in the marketplace is a challenge, thus genetically and chemically authenticated GI was not available in sufficient quantities for in vivo evaluations. Therefore, only authenticated and fully characterized GG and GU extracts were prepared for the in vivo study. A high dose of $1.3 \mathrm{~g}$ extract $/ \mathrm{kg} \mathrm{BW}$ per day was employed, as the clinically relevant dose $(65 \mathrm{mg} / \mathrm{kg}$ BW per day) did not enhance NQO1 activity in vivo (data not shown). The doses of $\operatorname{LigC}$ and $\mathrm{LigF}$ were calculated to mimic the contents of the high dose of GG extract, which is characterized by a higher amount of LigC equivalents than GU (Table 1). The administered GG and GU extracts contained mainly the glycosylated forms of LigC and LigF and only a small portion of the extracts were aglycones (Figure 5A and Figure S5, Table 1). However, in vivo, only LigC and LigF aglycones (Figure 5A, Figure S5) and their metabolites (data not shown) were detectable suggesting the hydrolysis of LigC/ LigF glycosides in vivo. Deglycosylation can occur in digestive tract starting from stomach with a low $\mathrm{pH}$, although the current literature reports are controversial. ${ }^{43}$ There are also limited information on the absorption and pharmacokinetics of various glycosides in comparison to their unconjugated counterparts in licorice extracts. ${ }^{70}$ Interestingly, LigC and LigF, which also have estrogenic properties, ${ }^{25}$ were distributed to mammary glands (Figure 5A, Figure 5B, Figure S5). Recent pharmacokinetic studies have shown that the bioavailability of $\mathrm{LigC}$ is relatively low due to its conversion to $\mathrm{LigF}$ as well as its fast and extensive metabolism. ${ }^{25}, 30,71$ Our data also showed that in $\mathrm{LigC}$ treated animals, $\mathrm{LigC}$ is mainly converted to LigF (Figure 5B). Extensive rapid metabolism, cyclization, and the interaction with glutathione could contribute to the negligible induction of NQO1 with free LigC (Figure 5B, Figure 6). However, in animals treated with extracts, in which glycosylated forms of $\mathrm{LigC}$ and $\mathrm{LigF}$ are abundant, $\mathrm{LigC}$ might be protected from rapid conversion to LigF. This may lead to a longer and sustained availability of LigC. Hence, GG extract, containing more LigC glycosides compared to GU, was able to induce NQO1 in vivo (Table 1, Figure 5A, Figure S5, Figure 6). For example, in serum higher total LigC concentrations were observed after application of GG extract $(10.28 \mu \mathrm{g} / \mathrm{mL})$, while the levels of LigC in the samples treated with the equivalent purified LigC was below the limit of quantification. In addition, matrix effects of the extract might play a role in providing higher $\mathrm{LigC}$ serum concentrations after GG administration compared to purified LigC. Also, it is noteworthy that there might be some other active components in the GG extract, different from $\mathrm{LigC}$, that may contribute to the higher NQO1 induction.

$\mathrm{LigC}$ as a Michael acceptor, has been shown to form glutathione conjugates in rat liver. ${ }^{42}$ GSH conjugates of Michael acceptors are often reversible which could suggest that LigC GSH conjugates could regenerate $\mathrm{LigC}$ in tissues where GSH concentrations are low (i.e., mammary gland). ${ }^{72}, 73$ The higher NQO1 induction by GG in the mammary gland compared to the liver might be associated with the lower levels of glutathione leading to more available free $\mathrm{LigC}$ in mammary tissue to induce NQO1. In addition, the different electrophilicities of the chalcones ( $\mathrm{LigC}, \mathrm{LicA})$ towards glutathione as well as other biological targets need to be considered in future studies. 
The minimal NQO1 induction observed in vivo, could be due to several factors. Oral administration of the extracts and LigC results in extensive degradation and Phase I and Phase II metabolism throughout the GI track. ${ }^{42}, 71$ In addition, $\mathrm{LigC}$ is prone to rapid cyclization to LigF (Figure 1B). ${ }^{30}$ All of these transformations result in low free LigC concentration ( $<$ limit of quantitation). Glycosylated LigC in the extracts might be hydrolyzed to the aglycone throughout the digestive tract and liver; however, hydroxylation and extensive glucoronidation of the $\mathrm{LigC}$ aglycone leads to low bioavailability of $\mathrm{LigC}{ }^{71}, 74$ It was previously shown that dietary administration of much higher doses of $\operatorname{LigC}(10 \mathrm{~g} / \mathrm{kg})$ in a long-term animal study (85 days) caused a small but significant NQO1 induction in the colon and mammary gland of female Sprague-Dawley rats. ${ }^{42}$ However, this study also described extensive metabolism of $\mathrm{LigC}$, which might have ultimately impacted the chemopreventive outcomes. ${ }^{42}$ It should be noted that the effects observed with licorice and its bioactive compounds in a four day rat study could be very different from the outcomes that might be observed in menopausal women taking them over a long period of time. Considering the in vitro data and the minimal induction of NQO1 by GG in the mammary tissue, the chemopreventive potential of licorice and its bioactive compounds needs further evaluations before recommending licorice supplements for chemoprevention in women. This recommendation will depend on having fully characterized extracts that are precisely standardized to their well studied bioactive compounds.

In conclusion, our in vitro comparison of three authenticated Glycyrrhiza species suggests that the electrophilic compounds such as $\mathrm{LigC}$ and LicA could contribute to the activation of detoxification enzymes through the Keap1-Nrf2 pathway. However, LicA might employ an additional mechanism as an AhR antagonist which could modulate NQO1 through parallel yet opposing effects on ARE and XRE elements. In addition, comparison with known chemopreventive compounds, such as sulforaphane, curcumin, and $\mathrm{XH}$ showed the following rank order of NQO1 induction; sulforaphane $>>\mathrm{XH}>\mathrm{LigC}>\mathrm{LicA} \approx$ curcumin >> LigF. The bioactive compounds $\operatorname{LigF}$ and $\operatorname{LigC}$ were detectable in the liver and mammary gland of rats treated with GG; however, the amount of the aglycones are very low and significant NQO1 induction was only observed in the mammary gland. This study clearly demonstrates the differential roles of Michael acceptors, LigC and LicA, in exerting chemopreventive effects by licorice extracts in vitro and it shows the weak NQO1 induction by GG in vivo. Further experiments are planned to test the NQO1 in vivo induction potential of GI and LicA especially since the chemical profile and biological activities are likely quite different.

Although the in vivo effects of GG and GU in the rat model are minimal, it must be emphasized that menopausal women take these supplements for extended periods of time and long-term efficacy is currently unknown. Finally, this study further emphasizes the importance of standardization and chemical/biological characterization of botanical supplements to their specific bioactive compounds.

\section{Supplementary Material}

Refer to Web version on PubMed Central for supplementary material. 


\section{Acknowledgement}

The authors thank Sarah E. Green for assistance with the in vivo experiments. The authors also thank Mr. Harald Schwarz and Dr. Martin Biendl from Hopsteiner (S. S. Steiner, New York, NY and Steiner Hopfen GmbH, Mainburg, Germany) for providing the hops extracts, and Dr. Liang Zhao from Lanzhou Institute of Chemical Physics, Lanzhou, China, for providing Glycyrrhiza inflata material as a generous gift. The stably transfected HepG2-ARE-C8 cells were a generous gift from Dr. Tony Kong's laboratory (Rutgers, Piscataway, HJ.).

Funding information

This research was supported by the NIH grant P50AT00155 from the Office of Dietary Supplements (ODS) and the National Center for Complementary \& Integrative Health $(\mathrm{NCCIH})$, formerly NCCAM.

\section{Abbreviations}

$\begin{array}{ll}\text { ARE } & \text { antioxidant response element } \\ \text { BF } & 4^{\prime} \text {-bromoflavone } \\ \text { CD } & \text { concentration doubling the NQO1 activity } \\ \text { GG } & \text { Glycyrrhiza glabra } \\ \text { GU } & \text { Glycyrrhiza uralensis } \\ \text { GI } & \text { Glycyrrhiza inflata } \\ \text { LicA } & \text { licochalcone A } \\ \text { LigC } & \text { isoliquiritigenin } \\ \text { LigF } & \text { liquiritigenin } \\ \text { NQO1 } & \text { NAD(P)H:quinone oxidoreductase 1 } \\ \text { SFN } & \text { sulforaphane } \\ \text { XH } & \text { xanthohumol }\end{array}$

\section{References}

1. Rossouw JE, Anderson GL, Prentice RL, LaCroix AZ, Kooperberg C, Stefanick ML, Jackson RD, Beresford SA, Howard BV, Johnson KC, Kotchen JM, Ockene J. Risks and benefits of estrogen plus progestin in healthy postmenopausal women: principal results From the Women's Health Initiative randomized controlled trial. JAMA. 2002; 288:321-333. [PubMed: 12117397]

2. Rees M. Alternative treatments for the menopause. Best Pract. Res. Clin. Obstet. Gynaecol. 2009; 23:151-161. [PubMed: 19010734]

3. Geller SE, Studee L. Botanical and dietary supplements for menopausal symptoms: what works, what does not. J. Womens Health. 2005; 14:634-649.

4. Hajirahimkhan A, Dietz BM, Bolton JL. Botanical modulation of menopausal symptoms: mechanisms of action? Planta Med. 2013; 79:538-553. [PubMed: 23408273]

5. Harman SM. Estrogen replacement in menopausal women: recent and current prospective studies, the WHI and the KEEPS. Gender Med. 2006; 3:254-269.

6. Rebbeck TR, Troxel AB, Norman S, Bunin GR, DeMichele A, Baumgarten M, Berlin M, Schinnar $\mathrm{R}$, Strom BL. A retrospective case-control study of the use of hormone-related supplements and association with breast cancer. Int. J. Cancer. 2007; 120:1523-1528. [PubMed: 17205521] 
7. Ungvari Z, Bailey-Downs L, Sosnowska D, Gautam T, Koncz P, Losonczy G, Ballabh P, de Cabo R, Sonntag WE, Csiszar A. Vascular oxidative stress in aging: a homeostatic failure due to dysregulation of NRF2-mediated antioxidant response. Am. J. Physiol. Heart Circ. Physiol. 2011; 301:H363-372. [PubMed: 21602469]

8. Zhu J, Wang H, Fan Y, Lin Y, Zhang L, Ji X, Zhou M. Targeting the NF-E2-related factor 2 pathway: a novel strategy for glioblastoma (review). Oncol. Rep. 2014; 32:443-450. [PubMed: 24926991]

9. Dietz BM, Hagos GK, Eskra JN, Wijewickrama GT, Anderson JR, Nikolic D, Guo J, Wright B, Chen SN, Pauli GF, van Breemen RB, Bolton JL. Differential regulation of detoxification enzymes in hepatic and mammary tissue by hops (Humulus lupulus) in vitro and in vivo. Mol. Nutr. Food Res. 2013; 57:1055-1066. [PubMed: 23512484]

10. Dietz BM, Kang YH, Liu G, Eggler AL, Yao P, Chadwick LR, Pauli GF, Farnsworth NR, Mesecar $\mathrm{AD}$, van Breemen RB, Bolton JL. Xanthohumol isolated from Humulus lupulus inhibits menadione-induced DNA damage through induction of quinone reductase. Chem. Res. Toxicol. 2005; 18:1296-1305. [PubMed: 16097803]

11. Balogun E, Hoque M, Gong P, Killeen E, Green CJ, Foresti R, Alam J, Motterlini R. Curcumin activates the haem oxygenase-1 gene via regulation of Nrf2 and the antioxidant-responsive element. Biochem. J. 2003; 371:887-895. [PubMed: 12570874]

12. Gafner S, Lee SK, Cuendet M, Barthelemy S, Vergnes L, Labidalle S, Mehta RG, Boone CW, Pezzuto JM. Biologic evaluation of curcumin and structural derivatives in cancer chemoprevention model systems. Phytochemistry. 2004; 65:2849-2859. [PubMed: 15501252]

13. Shen G, Xu C, Hu R, Jain MR, Gopalkrishnan A, Nair S, Huang MT, Chan JY, Kong AN. Modulation of nuclear factor E2-related factor 2-mediated gene expression in mice liver and small intestine by cancer chemopreventive agent curcumin. Mol. Cancer Ther. 2006; 5:39-51. [PubMed: 16432161]

14. Francy-Guilford J, Pezzuto JM. Mechanisms of cancer chemopreventive agents: a perspective. Planta Med. 2008; 74:1644-1650. [PubMed: 18537076]

15. Kong AN, Owuor E, Yu R, Hebbar V, Chen C, Hu R, Mandlekar S. Induction of xenobiotic enzymes by the MAP kinase pathway and the antioxidant or electrophile response element (ARE/ EpRE). Drug Metab. Rev. 2001; 33:255-271. [PubMed: 11768769]

16. Juge N, Mithen RF, Traka M. Molecular basis for chemoprevention by sulforaphane: a comprehensive review. Cell. Mol. Life Sci. 2007; 64:1105-1127. [PubMed: 17396224]

17. Cheung KL, Kong AN. Molecular targets of dietary phenethyl isothiocyanate and sulforaphane for cancer chemoprevention. AAPS J. 2010; 12:87-97. [PubMed: 20013083]

18. Liu G, Eggler AL, Dietz BM, Mesecar AD, Bolton JL, Pezzuto JM, van Breeman RB. A screening method for the discovery of potential cancer chemoprevention agents based on mass spectrometric detection of alkylated Keap1. Anal. Chem. 2005; 77:6407-6414. [PubMed: 16194107]

19. Eggler AL, Gay KA, Mesecar AD. Molecular mechanisms of natural products in chemoprevention: induction of cytoprotective enzymes by Nrf2. Mol. Nutr. Food Res. 2008; 52(Suppl 1):S84-94. [PubMed: 18435489]

20. Shibata S. A drug over the millennia: pharmacognosy, chemistry, and pharmacology of licorice. Yakugaku Zasshi. 2000; 120:849-862. [PubMed: 11082698]

21. Messier C, Epifano F, Genovese S, Grenier D. Licorice and its potential beneficial effects in common oro-dental diseases. Oral Dis. 2012; 18:32-39. [PubMed: 21851508]

22. Liu HM, Sugimoto N, Akiyama T, Maitani T. Constituents and their sweetness of food additive enzymatically modified licorice extract. J. Agric. Food Chem. 2000; 48:6044-6047. [PubMed: 11312777]

23. Simmler C, Anderson JR, Gauthier L, Lankin DC, McAlpine JB, Chen SN, Pauli GF. Metabolite profiling and classification of DNA authenticated licorice botanicals. J. Nat. Prod. 2015 In press.

24. Farag MA, Porzel A, Wessjohann LA. Comparative metabolite profiling and fingerprinting of medicinal licorice roots using a multiplex approach of GCMS, LC-MS and 1D NMR techniques. Phytochemistry. 2012; 76:60-72. [PubMed: 22336263]

25. Hajirahimkhan A, Simmler C, Yuan Y, Anderson JR, Chen SN, Nikolic D, Dietz BM, Pauli GF, van Breemen RB, Bolton JL. Evaluation of estrogenic activity of licorice species in comparison 
with Hops used in botanicals for menopausal symptoms. PLoS One. 2013; 8:e67947. [PubMed: 23874474]

26. Dunlap TL, Wang S, Simmler C, Chen SN, Pauli GF, Dietz BM, Bolton JL. Differential effects of Glycyrrhiza species on genotoxic estrogen metabolism: licochalconeA downregulates P450 1B1 whereas isoliquiritigenin stimulates. Chem. Res. Toxicol. 2015 In press.

27. Kondo K, Shiba M, Yamaji H, Morota T, Zhengmin C, Huixia P, Shoyama Y. Species identification of licorice using nrDNA and cpDNA genetic markers. Biol. Pharm. Bull. 2007; 30:1497-1502. [PubMed: 17666810]

28. Kondo K, Shiba M, Nakamura R, Morota T, Shoyama Y. Constituent properties of licorices derived from Glycyrrhiza uralensis, Glycyrrhiza glabra, or Glycyrrhiza inflata identified by genetic information. Biol. Pharm. Bull. 2007; 30:1271-1277. [PubMed: 17603166]

29. Simmler C, Nikolic D, Lankin DC, Yu Y, Friesen JB, van Breemen RB, Lecomte A, Le Quemener C, Audo G, Pauli GF. Orthogonal analysis underscores the relevance of primary and secondary metabolites in licorice. J. Nat. Prod. 2014; 77:1806-1816. [PubMed: 25080313]

30. Simmler C, Hajirahimkhan A, Lankin DC, Bolton JL, Jones T, Soejarto DD, Chen C, Pauli GF. Dynamic residual complexity of the isoliquiritigenin-liquiritigenin interconversion during bioassay. J. Agric. Food Chem. 2013; 61:2146-2157. [PubMed: 23427769]

31. Cuendet M, Oteham CP, Moon RC, Pezzuto JM. Quinone reductase induction as a biomarker for cancer chemoprevention. J. Nat. Prod. 2006; 69:460-463. [PubMed: 16562858]

32. Mersereau JE, Levy N, Staub RE, Baggett S, Zogovic T, Chow S, Ricke WA, Tagliaferri M, Cohen I, Bjeldanes LF, Leitman DC. Liquiritigenin is a plant-derived highly selective estrogen receptor beta agonist. Mol. Cell. Endocrinol. 2008; 283:49-57. [PubMed: 18177995]

33. Matthews J, Gustafsson J-A. Estrogen Signaling: A Subtle Balance Between ERa and ERb. Mol. Interv. 2003; 3:281-292. [PubMed: 14993442]

34. Simmler C, Jones T, Anderson JR, Nikolic DC, van Breemen RB, Soejarto DD, Chen SN, Pauli GF. Species-specific Standardisation of Licorice by Metabolomic Profiling of Flavanones and Chalcones. Phytochem. Anal. 2014; 25:378-388. [PubMed: 25859589]

35. Chadwick LR, Nikolic D, Burdette JE, Overk CR, Bolton JL, van Breemen RB, Frohlich R, Fong HH, Farnsworth NR, Pauli GF. Estrogens and congeners from spent hops (Humulus lupulus). J. Nat. Prod. 2004; 67:2024-2032. [PubMed: 15620245]

36. Hemachandra LP, Madhubhani P, Chandrasena R, Esala P, Chen SN, Main M, Lankin DC, Scism RA, Dietz BM, Pauli GF, Thatcher GR, Bolton JL. Hops (Humulus lupulus) inhibits oxidative estrogen metabolism and estrogen-induced malignant transformation in human mammary epithelial cells (MCF-10A). Cancer Prev. Res. 2012; 5:73-81.

37. Simmler C, Nikolic D, Lankin DC, Yu Y, Friesen JB, van Breemen RB, Lecomte A, Le Quemener C, Audo G, Pauli GF. Orthogonal Analysis Underscores the Relevance of Primary and Secondary Metabolites in Licorice. J. Nat. Prod. 2014

38. Pauli GF, Chen SN, Simmler C, Lankin DC, Godecke T, Jaki BU, Friesen JB, McAlpine JB, Napolitano JG. Importance of purity evaluation and the potential of quantitative (1)h NMR as a purity assay. J. Med. Chem. 2014; 57:9220-9231. [PubMed: 25295852]

39. Prochaska HJ, Santamaria AB. Direct measurement of NAD $(\mathrm{P}) \mathrm{H}$ :quinone reductase from cells cultured in microtiter wells: A screening assay for anticarcinogenic enzyme inducers. Anal. Biochem. 1988; 169:328-336. [PubMed: 3382006]

40. Gerhauser C, You M, Liu J, Moriarty RM, Hawthorne M, Mehta RG, Moon RC, Pezzuto JM. Cancer chemopreventive potential of sulforamate, a novel analogue of sulforaphane that induces phase 2 drug-metabolizing enzymes. Cancer Res. 1997; 57:272-278. [PubMed: 9000567]

41. Keum YS, Yu S, Chang PP, Yuan X, Kim JH, Xu C, Han J, Agarwal A, Kong AN. Mechanism of action of sulforaphane: inhibition of $\mathrm{p} 38$ mitogen-activated protein kinase isoforms contributing to the induction of antioxidant response element-mediated heme oxygenase-1 in human hepatoma HepG2 cells. Cancer Res. 2006; 66:8804-8813. [PubMed: 16951197]

42. Cuendet M, Guo J, Luo Y, Chen S, Oteham CP, Moon RC, van Breemen RB, Marler LE, Pezzuto JM. Cancer chemopreventive activity and metabolism of isoliquiritigenin, a compound found in licorice. Cancer Prev. Res. 2010; 3:221-232. 
43. Kamei J, Saitoh A, Asano T, Nakamura R, Ichiki H, Iiduka A, Kubo M. Pharmacokinetic and pharmacodynamic profiles of the antitussive principles of Glycyrrhizae radix (licorice), a main component of the Kampo preparation Bakumondo-to (Mai-men-dong-tang). Eur. J. Pharmacol. 2005; 507:163-168. [PubMed: 15659306]

44. Gullett NP, Ruhul Amin AR, Bayraktar S, Pezzuto JM, Shin DM, Khuri FR, Aggarwal BB, Surh YJ, Kucuk O. Cancer prevention with natural compounds. Semin. Oncol. 2010; 37:258-281. [PubMed: 20709209]

45. Aggarwal BB, Shishodia S. Molecular targets of dietary agents for prevention and therapy of cancer. Biochem. Pharmacol. 2006; 71:1397-1421. [PubMed: 16563357]

46. Kang YH, Pezzuto JM. Induction of quinone reductase as a primary screen for natural product anticarcinogens. Methods Enzymol. 2004; 382:380-414. [PubMed: 15047113]

47. Chen C, Kong AN. Dietary chemopreventive compounds and ARE/EpRE signaling. Free Radic. Biol. Med. 2004; 36:1505-1516. [PubMed: 15182853]

48. Song LL, Kosmeder JW 2nd, Lee SK, Gerhauser C, Lantvit D, Moon RC, Moriarty RM, Pezzuto JM. Cancer chemopreventive activity mediated by $4^{\prime}$-bromoflavone, a potent inducer of phase II detoxification enzymes. Cancer Res. 1999; 59:578-585. [PubMed: 9973203]

49. Jo EH, Hong HD, Ahn NC, Jung JW, Yang SR, Park JS, Kim SH, Lee YS, Kang KS. Modulations of the Bcl-2/Bax family were involved in the chemopreventive effects of licorice root (Glycyrrhiza uralensis Fisch) in MCF-7 human breast cancer cell. J. Agric. Food Chem. 2004; 52:1715-1719. [PubMed: 15030235]

50. Wu TY, Khor TO, Saw CL, Loh SC, Chen AI, Lim SS, Park JH, Cai L, Kong AN. Antiinflammatory/Anti-oxidative stress activities and differential regulation of Nrf2-mediated genes by non-polar fractions of tea Chrysanthemum zawadskii and licorice Glycyrrhiza uralensis. AAPS J. 2011; 13:1-13. [PubMed: 20967519]

51. Tsai JP, Hsiao PC, Yang SF, Hsieh SC, Bau DT, Ling CL, Pai CL, Hsieh YH. Licochalcone A suppresses migration and invasion of human hepatocellular carcinoma cells through downregulation of MKK4/JNK via NF-kappaB mediated urokinase plasminogen activator expression. PLoS One. 2014; 9:e86537. [PubMed: 24466137]

52. Webb TE, Stromberg PC, Abou-Issa H, Curley RW Jr. Moeschberger M. Effect of dietary soybean and licorice on the male F344 rat: an integrated study of some parameters relevant to cancer chemoprevention. Nutr. Cancer. 1992; 18:215-230. [PubMed: 1296195]

53. Takahashi T, Takasuka N, Iigo M, Baba M, Nishino H, Tsuda H, Okuyama T. Isoliquiritigenin, a flavonoid from licorice, reduces prostaglandin E2 and nitric oxide, causes apoptosis, and suppresses aberrant crypt foci development. Cancer Sci. 2004; 95:448-453. [PubMed: 15132774]

54. Asl MN, Hosseinzadeh H. Review of pharmacological effects of Glycyrrhiza sp. and its bioactive compounds. Phytother. Res. 2008; 22:709-724. [PubMed: 18446848]

55. Jaramillo MC, Zhang DD. The emerging role of the Nrf2-Keap1 signaling pathway in cancer. Genes Dev. 2013; 27:2179-2191. [PubMed: 24142871]

56. Wakabayashi N, Slocum SL, Skoko JJ, Shin S, Kensler TW. When NRF2 talks, who's listening? Antioxid. Redox Signaling. 2010; 13:1649-1663.

57. Schnekenburger M, Karius T, Diederich M. Regulation of epigenetic traits of the glutathione Stransferase P1 gene: from detoxification toward cancer prevention and diagnosis. Front. Pharmacol. 2014; 5:170. [PubMed: 25076909]

58. Li C, Zhou Y. Association between NQO1 C609T polymorphism and acute lymphoblastic leukemia risk: evidence from an updated meta-analysis based on 17 case-control studies. J. Cancer Res. Clin. Oncol. 2014; 140:873-881. [PubMed: 24488035]

59. Eggler AL, Small E, Hannink M, Mesecar AD. Cul3-mediated Nrf2 ubiquitination and antioxidant response element (ARE) activation are dependent on the partial molar volume at position 151 of Keap1. Biochem. J. 2009; 422:171-180. [PubMed: 19489739]

60. Eggler AL, Liu G, Pezzuto JM, van Breemen RB, Mesecar AD. Modifying specific cysteines of the electrophile-sensing human Keap1 protein is insufficient to disrupt binding to the Nrf2 domain Neh2. Proc. Natl. Acad. Sci. U. S. A. 2005; 102:10070-10075. [PubMed: 16006525]

61. Zhang DD. Mechanistic studies of the Nrf2-Keap1 signaling pathway. Drug Metab. Rev. 2006; 38:769-789. [PubMed: 17145701] 
62. Dinkova-Kostova AT, Talalay P. NAD(P)H:quinone acceptor oxidoreductase 1 (NQO1), a multifunctional antioxidant enzyme and exceptionally versatile cytoprotector. Arch. Biochem. Biophys. 2010; 501:116-123. [PubMed: 20361926]

63. Nioi P, Hayes JD. Contribution of $\mathrm{NAD}(\mathrm{P}) \mathrm{H}$ :quinone oxidoreductase 1 to protection against carcinogenesis, and regulation of its gene by the Nrf2 basic-region leucine zipper and the arylhydrocarbon receptor basic helix-loop-helix transcription factors. Mutat. Res. 2004; 555:149171. [PubMed: 15476858]

64. Kohle C, Bock KW. Coordinate regulation of Phase I and II xenobiotic metabolisms by the Ah receptor and Nrf2. Biochem. Pharmacol. 2007; 73:1853-1862. [PubMed: 17266942]

65. Kalthoff S, Ehmer U, Freiberg N, Manns MP, Strassburg CP. Interaction between oxidative stress sensor Nrf2 and xenobiotic-activated aryl hydrocarbon receptor in the regulation of the human phase II detoxifying UDP-glucuronosyltransferase 1A10. J. Biol. Chem. 2010; 285:5993-6002. [PubMed: 20053997]

66. Miranda CL, Aponso GL, Stevens JF, Deinzer ML, Buhler DR. Prenylated chalcones and flavanones as inducers of quinone reductase in mouse Hepa 1c1c7 cells. Cancer Lett. 2000; 149:21-29. [PubMed: 10737704]

67. Menati L, Khaleghinezhad K, Tadayon M, Siahpoosh A. Evaluation of contextual and demographic factors on licorice effects on reducing hot flashes in postmenopause women. Health Care Women Int. 2014; 35:87-99. [PubMed: 23663094]

68. Nahidi F, Zare E, Mojab F, Alavi-Majd H. Effects of licorice on relief and recurrence of menopausal hot flashes. Iran J Pharm Res. 2012; 11:541-548. [PubMed: 24250477]

69. Yang L, Zahid M, Liao Y, Rogan EG, Cavalieri EL, Davidson NE, Yager JD, Visvanathan K, Groopman JD, Kensler TW. Reduced formation of depurinating estrogen-DNA adducts by sulforaphane or KEAP1 disruption in human mammary epithelial MCF-10A cells. Carcinogenesis. 2013; 34:2587-2592. [PubMed: 23843041]

70. Zuo F, Zhou ZM, Yan MZ, Liu ML, Xiong YL, Zhang Q, Song HY, Ye WH. Metabolism of constituents in Huangqin-Tang, a prescription in traditional Chinese medicine, by human intestinal flora. Biol. Pharm. Bull. 2002; 25:558-563. [PubMed: 12033492]

71. Choi YH, Kim YJ, Chae HS, Chin YW. In Vivo Gastroprotective Effect along with Pharmacokinetics, Tissue Distribution and Metabolism of Isoliquiritigenin in Mice. Planta Med. 2015; 81:586-593. [PubMed: 25875506]

72. Chandrasena RE, Edirisinghe PD, Bolton JL, Thatcher GR. Problematic detoxification of estrogen quinones by $\mathrm{NAD}(\mathrm{P}) \mathrm{H}$-dependent quinone oxidoreductase and glutathione-S-transferase. Chem Res Toxicol. 2008; 21:1324-1329. [PubMed: 18588320]

73. Randall MJ, Hristova M, van der Vliet A. Protein alkylation by the alpha,beta-unsaturated aldehyde acrolein. A reversible mechanism of electrophile signaling? FEBS Lett. 2013; 587:3808-3814. [PubMed: 24157358]

74. Lee YK, Chin Y-W, Bae J-K, Seo JS, Choi YH. Pharmacokinetics of Isoliquiritigenin and Its Metabolites in Rats: Low Bioavailability Is Primarily Due to the Hepatic and Intestinal Metabolism. Planta Med. 2013; 79:1656-1665. [PubMed: 24108436]

75. Gerhauser C, Klimo K, Heiss E, Neumann I, Gamal-Eldeen A, Knauft J, Liu GY, Sitthimonchai S, Frank N. Mechanism-based in vitro screening of potential cancer chemopreventive agents. Mutat. Res. 2003; 523-524:163-172. [PubMed: 12628514] 
A)<smiles>COc1cc(O)c(CC=C(C)C)c(O)c1C(=O)/C=C/c1ccc(O)cc1</smiles>

B)<smiles>Cc1ccc(C=CC(=O)c2ccc(O)cc2O)cc1</smiles><smiles>C=CC(C)(C)c1cc(/C=C/C(=O)c2ccc(O)cc2)c(O)cc1OC</smiles>

LicA<smiles>CC1(C)C=Cc2c(ccc3c2OCC(c2ccc(O)cc2O)C3)O1</smiles>

Figure 1.

Electrophilic compounds, A) XH from hops, curcumin from turmeric, and sulforaphane from broccoli, B) bioactive compounds from licorice species. 


\section{A)}

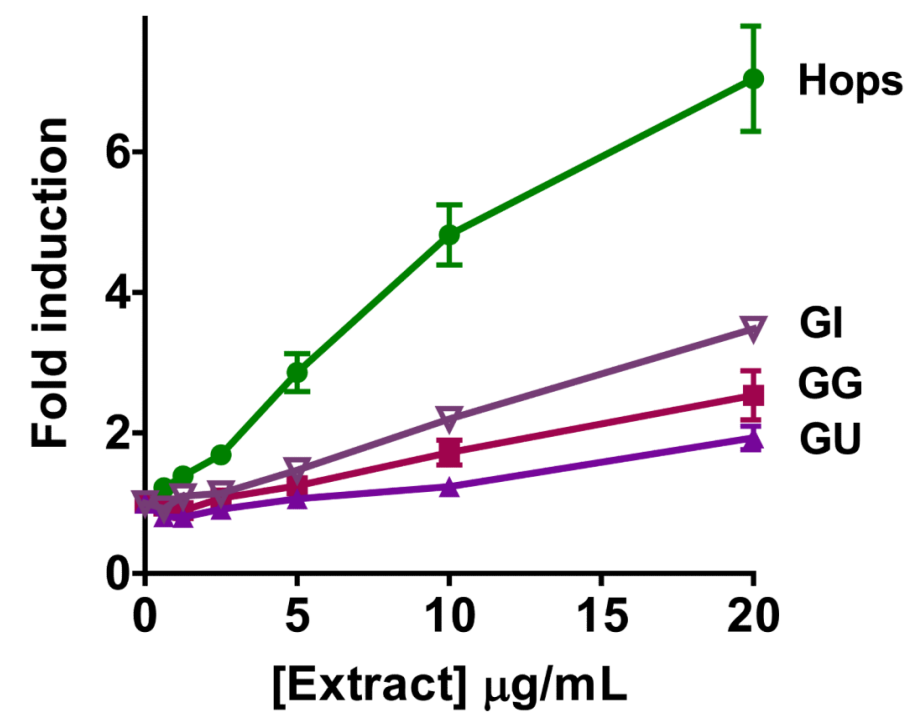

B)

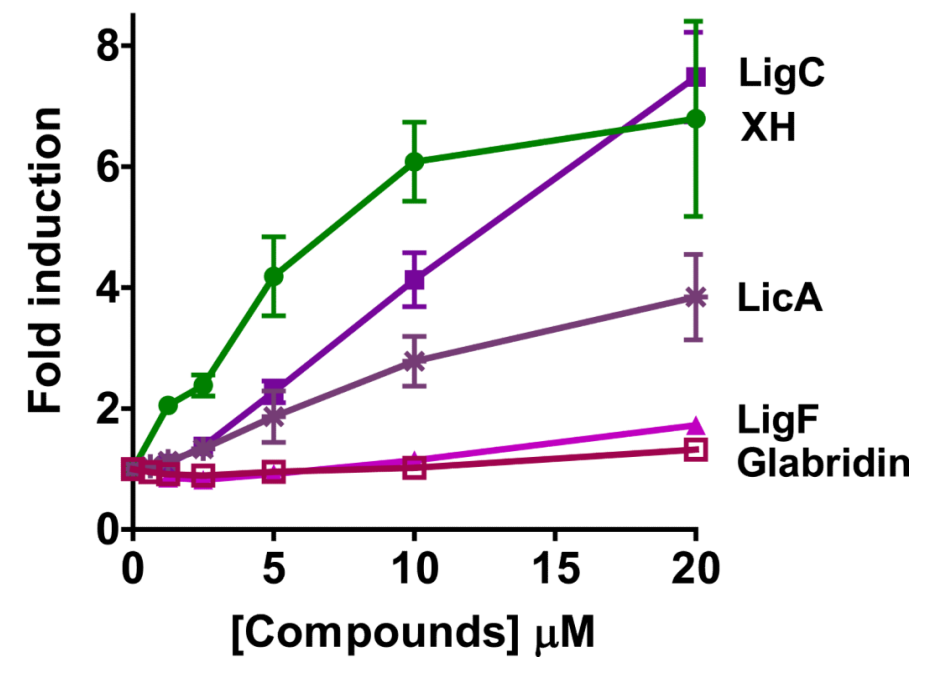

Figure 0002 
C)

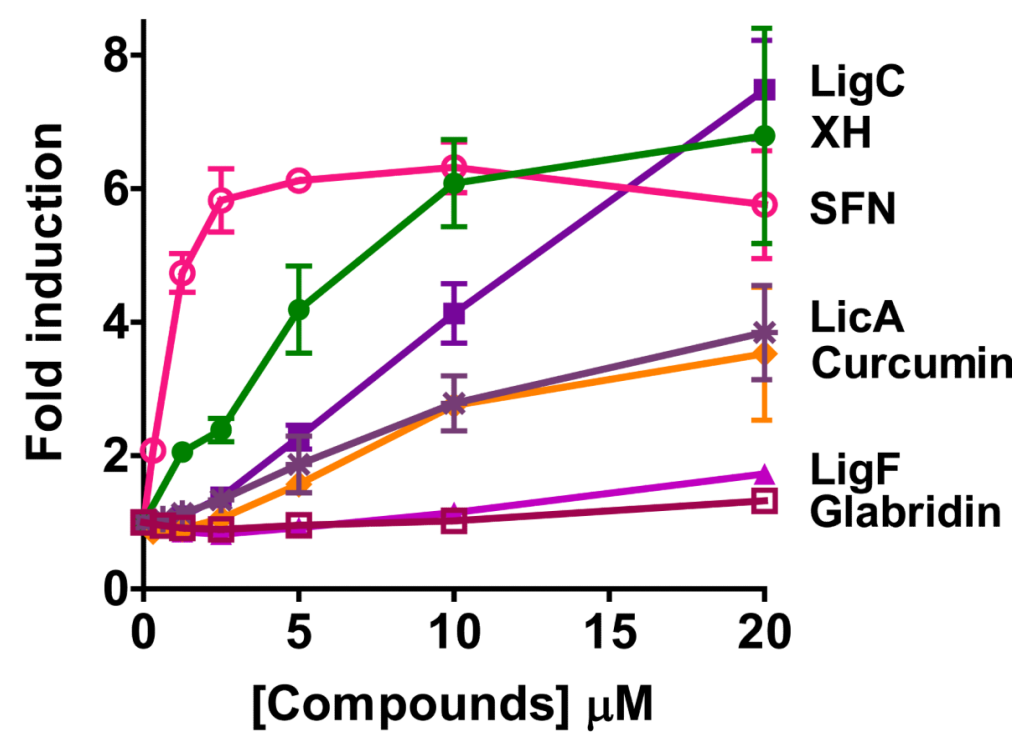

D)

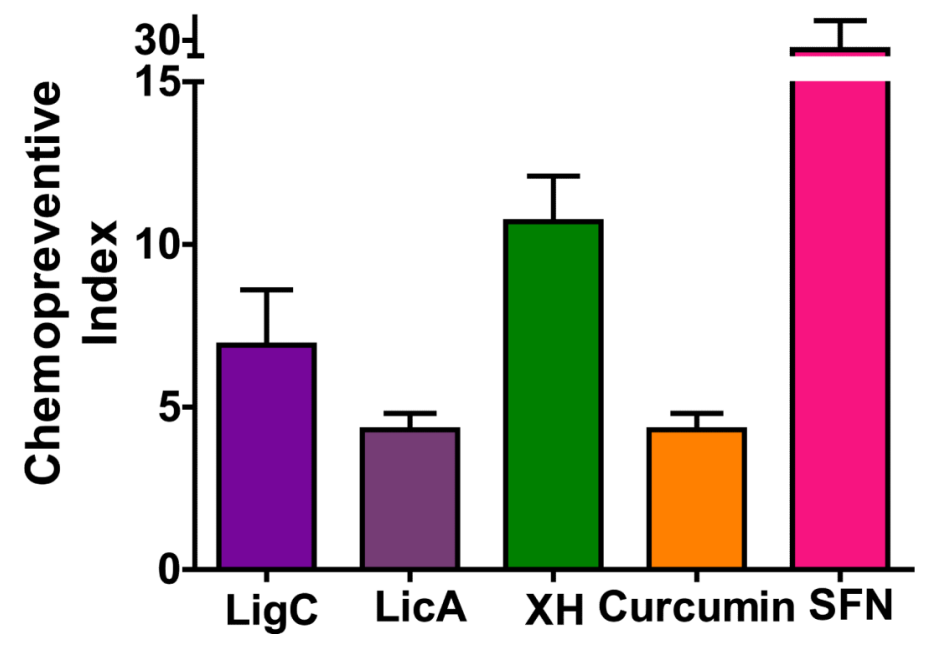

\section{Figure 0003}

Figure 2.

NQO1 activity in murine hepatoma hepa1c1c7 cells by A) licorice extracts from the three major species, GG, GU, and GI in comparison to hops extract. B) LigC/LigF, and LicA from licorice in comparison to $\mathrm{XH}$ from hops. C) Licorice bioactive constituents relative to $\mathrm{XH}$, curcumin from turmeric, and sulforaphane from broccoli sprouts. D) Chemopreventive index was calculated as the ratio of a compound's $\mathrm{LC}_{50}$ over its $\mathrm{CD}$ value in the $\mathrm{NQO} 1$ activity 
assay. Results are shown as fold induction and are the means of three independent determinations. 


\section{A)}

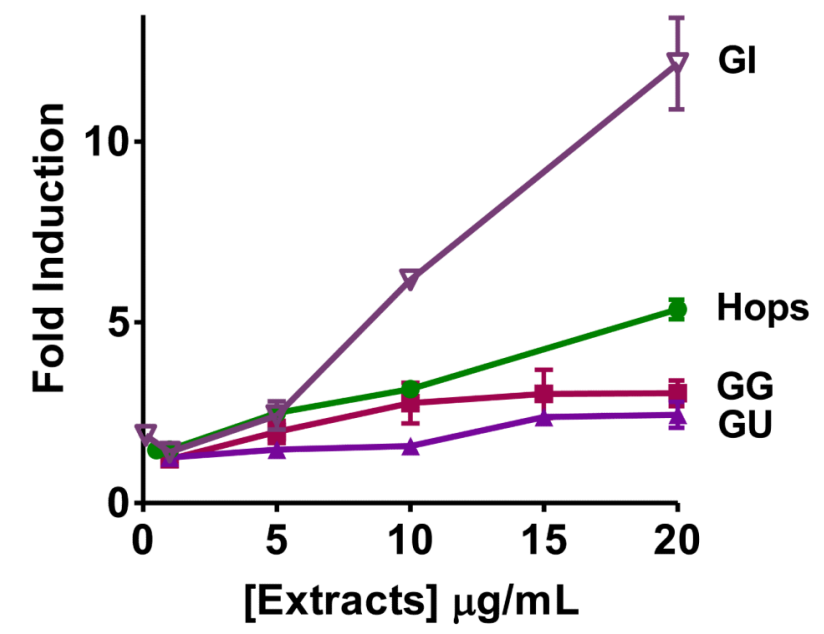

B)

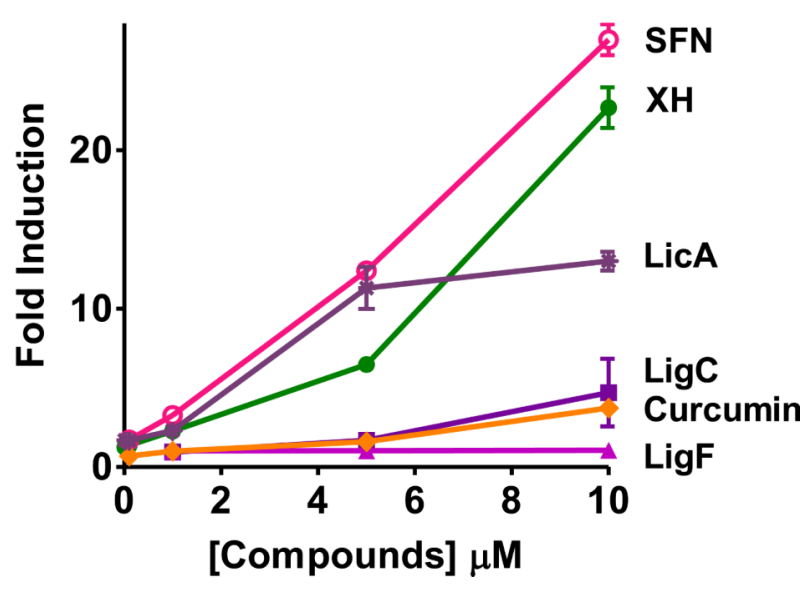

Figure 3.

Induction of ARE-luciferase in stably transfected human hepatoma Hep-G2-ARE-C8 cells by A) licorice extracts from the three major species, GG, GU, and GI in comparison to hops extract, B) by LigC/LigF, and LicA from licorice, $\mathrm{XH}$ from hops, curcumin from turmeric, sulforaphane from broccoli. Results are normalized to the corresponding protein concentrations and the DMSO control. Results are shown as fold induction and are the means of three independent determinations. 
A)

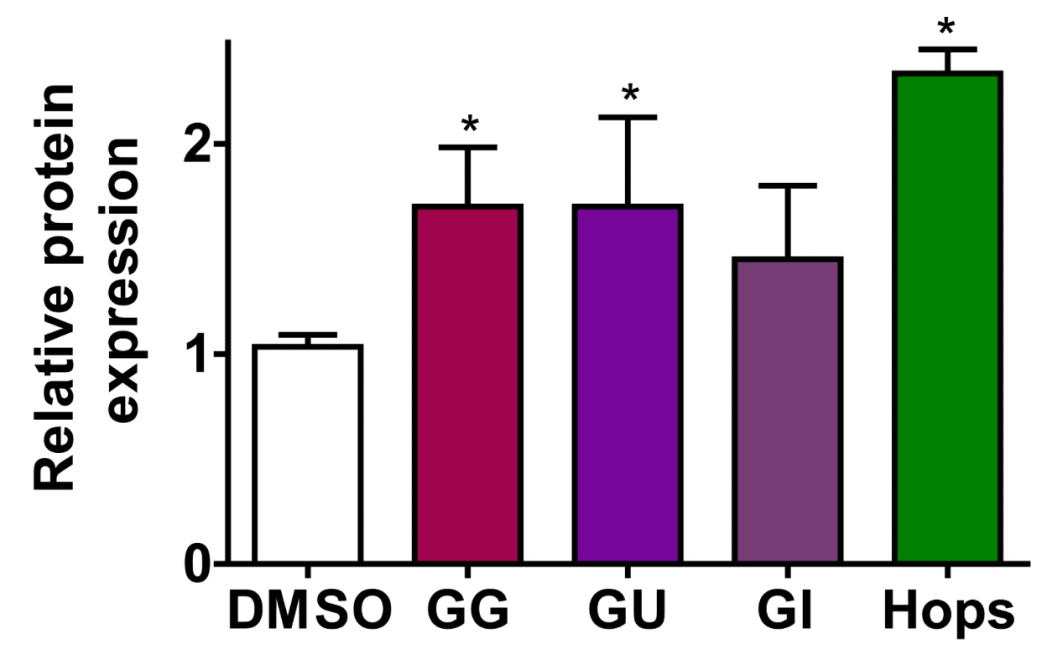

B)

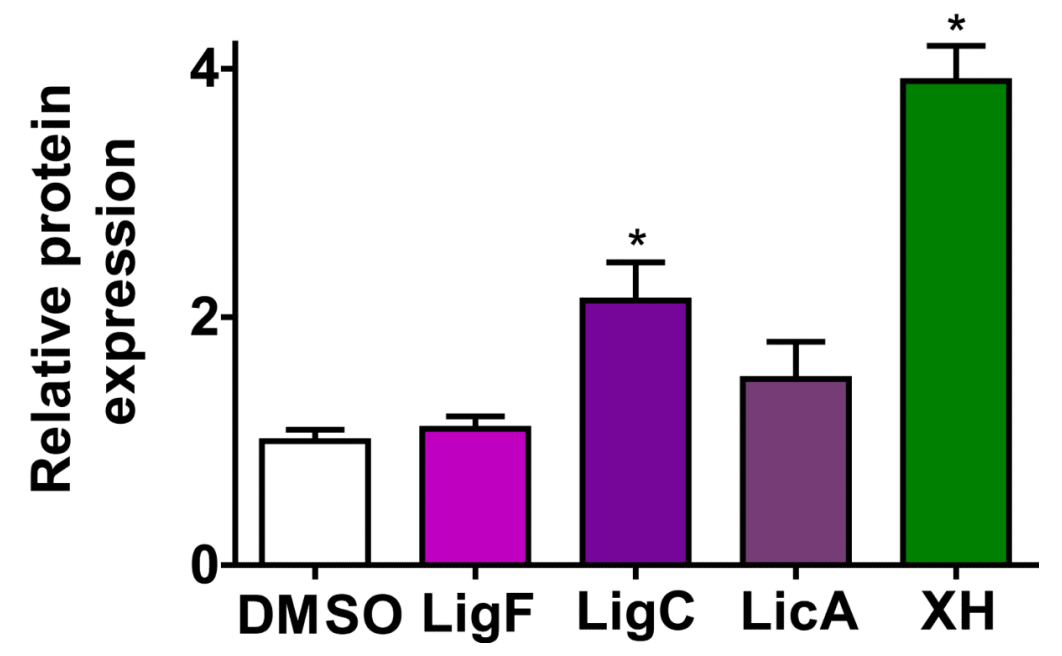

Figure 4.

Induction of NQO1 in non-tumorigenic ER (-) human mammary epithelial cells (MCF-10A). Quantitation of western blot analysis of the Induction of NQO1 in MCF-10A cells by A) crude extracts of $G$. glabra; $G G(10 \mu \mathrm{g} / \mathrm{mL}), G$. uralensis; $G U(10 \mu \mathrm{g} / \mathrm{mL}$, open bar), $G$. Inflata; $G I(10 \mu \mathrm{g} / \mathrm{mL})$ in comparison to hops extract $(5 \mu \mathrm{g} / \mathrm{mL})$ and B) characteristic compounds $\operatorname{LigC}(5 \mu \mathrm{M}), \operatorname{LigF}(10 \mu \mathrm{M})$, and $\operatorname{LicA}(5 \mu \mathrm{M})$ in comparison to $\mathrm{XH}(5 \mu \mathrm{M})$. Results are shown as fold induction and are the means of three independent determinations. 
A)

B)
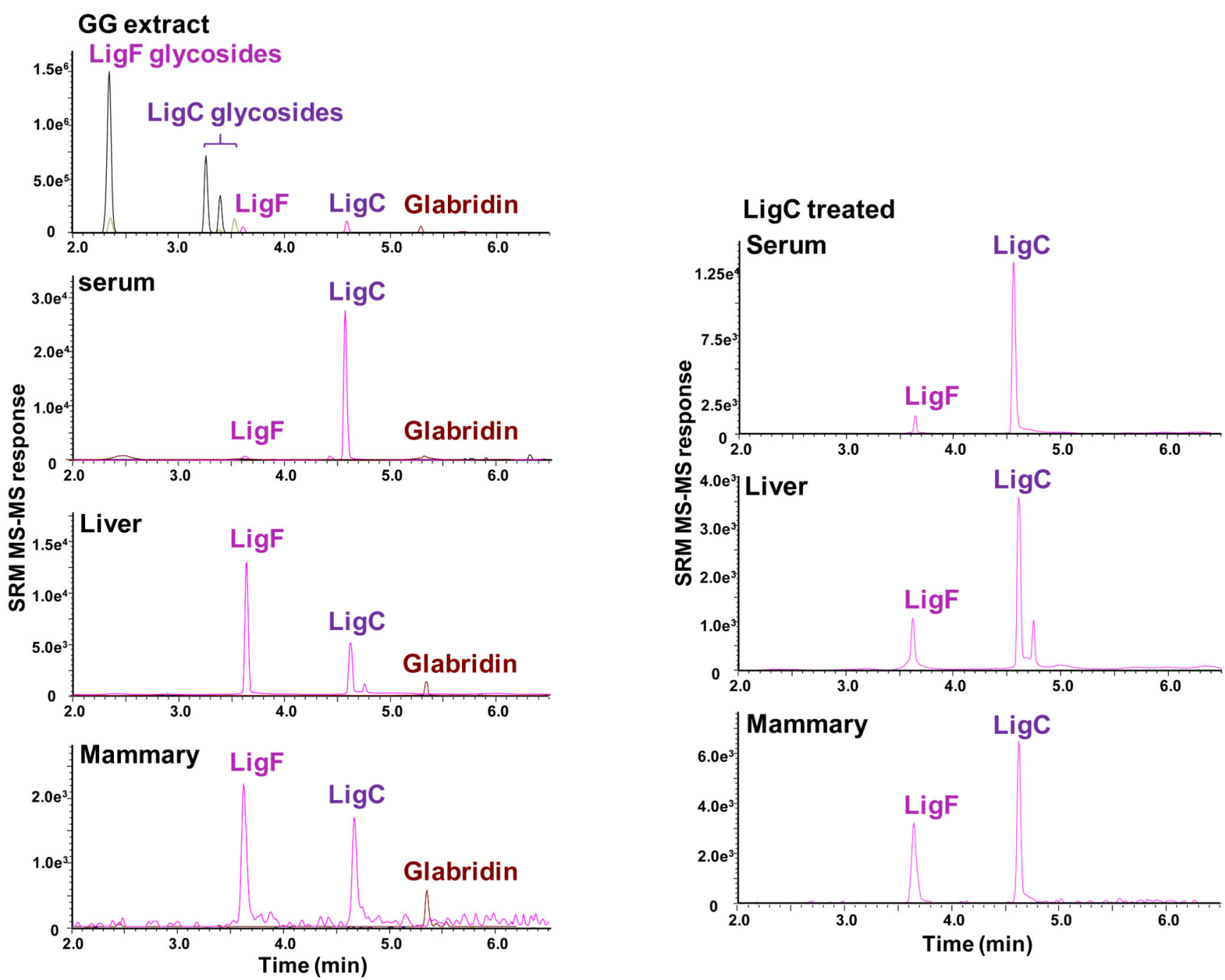

Figure 5.

LC-MS/MS SRM chromatograms of LigC/LigF tissue distribution A) in the GG extract and the $\mathrm{GG}$ treated animal tissues $\mathrm{B}$ ) in the $\mathrm{LigC}$ treated animal tissues. 
A)

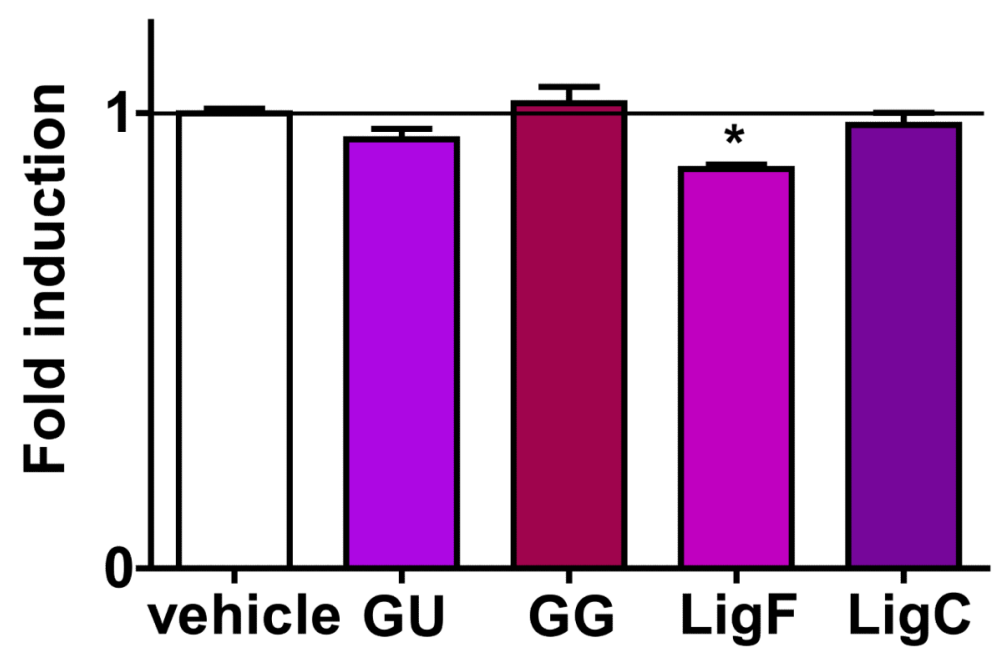

B)

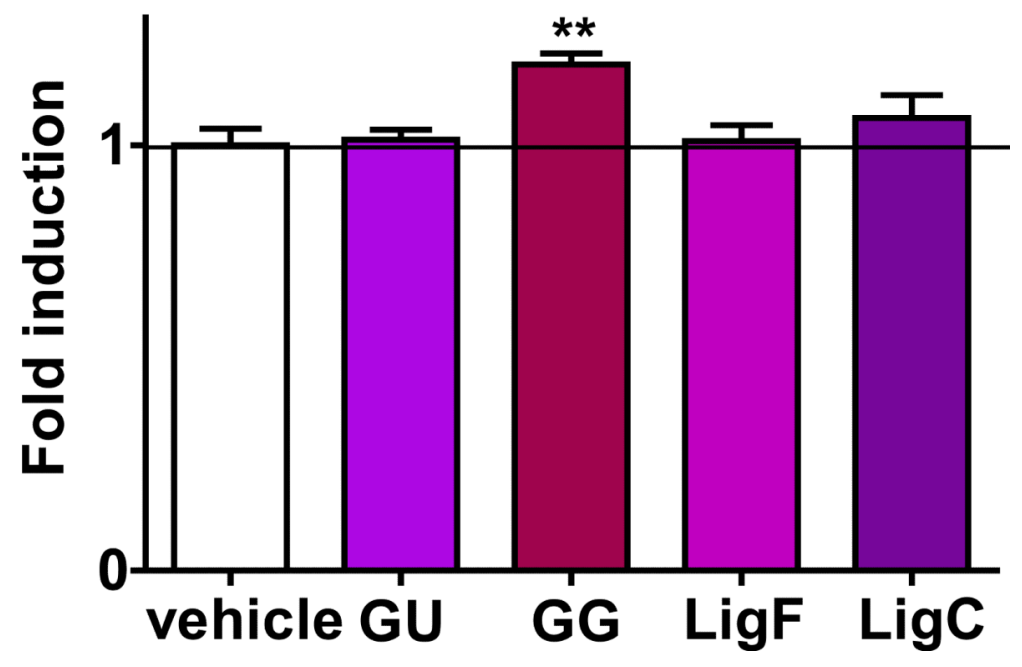

Figure 6.

The influence of licorice extracts and characteristic LigF and LigC on NQO1 induction in the A) liver and B) mammary glands. Animals were treated orally for 4 days with GG and GU at $1.3 \mathrm{~g} / \mathrm{kg} \mathrm{BW}$ per day, LigF at $80 \mathrm{mg} / \mathrm{kg} \mathrm{BW}$ per day, and LigC at $40 \mathrm{mg} / \mathrm{kg} \mathrm{BW}$ per day. 4'-Bromoflavone, the positive control was mixed in their diet at $150 \mathrm{mg} / \mathrm{kg}$ BW per day and induced NQO1 $4.47 \pm 0.13$ folds in the liver and $2.15 \pm 0.14$ folds in the mammary tissue. 
<smiles>C=CC(C)(C)c1cc(C#CCC(=O)c2ccc(O)cc2O)c(OC)cc1O</smiles>

\section{AhR antagonist}

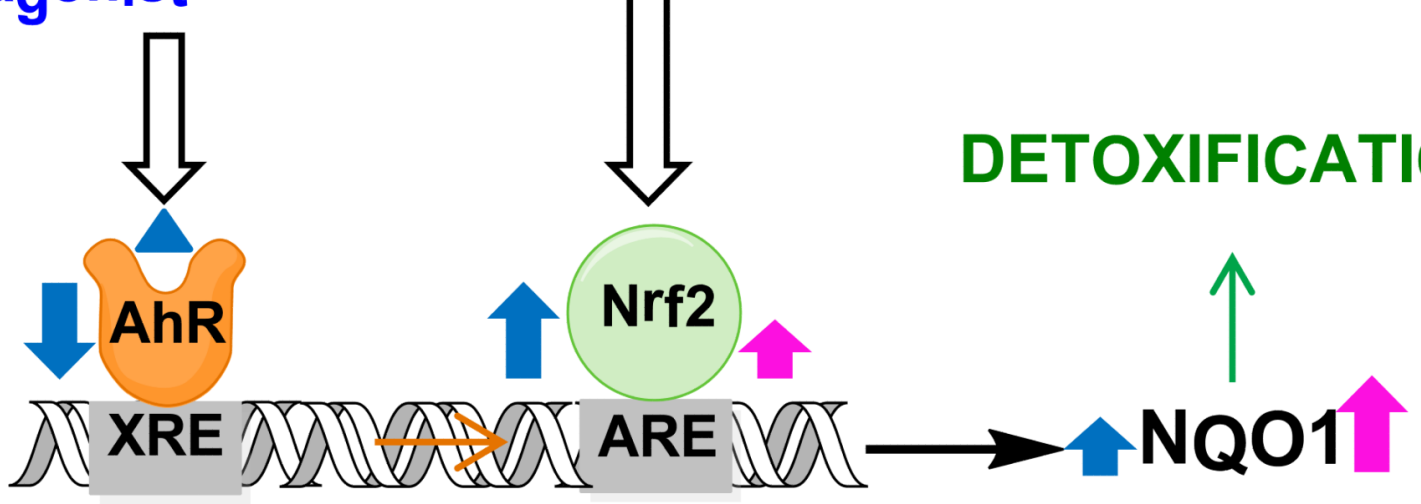

Scheme 1.

Michael acceptors LigC and LigF modulate NQO1 through different mechanisms based on the in vitro observations. The left side clear arrow with black borders shows the inhibitory effect of LicA on AhR pathway. The blue arrow shows the effect of LicA on Keap1-Nrf2 pathway and the induction of ARE and NQO1 by this compound. Pink arrow shows the effect of LigC on Keap1-Nrf2 pathway and the induction of ARE and NQO1 by this compound.

LigC interacts with Keap1 and the consequent translocation of Nrf2 to the nucleus and its interaction with ARE might result in NQO1 induction. LicA could influence the induction of NQO1 through two parallel, yet opposing molecular interactions at the promoter of NQO1. It can increase ARE induction through interacting with Keap1 and decrease XRE induction through inhibiting AhR, which might result in a lower NQO1 induction compared to that of LigC. 


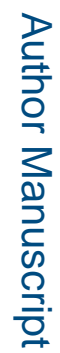

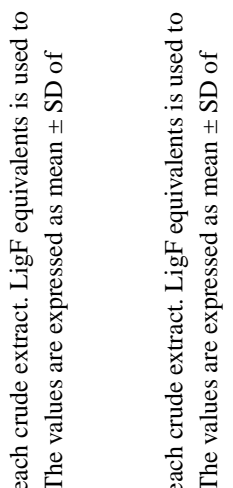

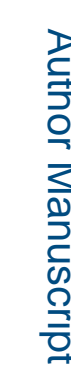

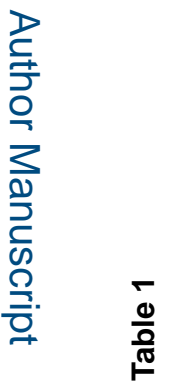

公

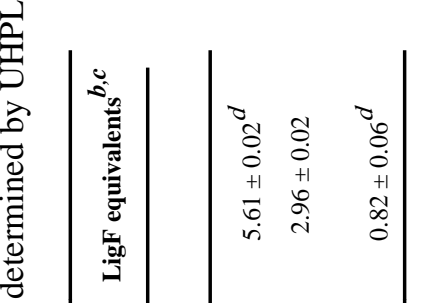

过 


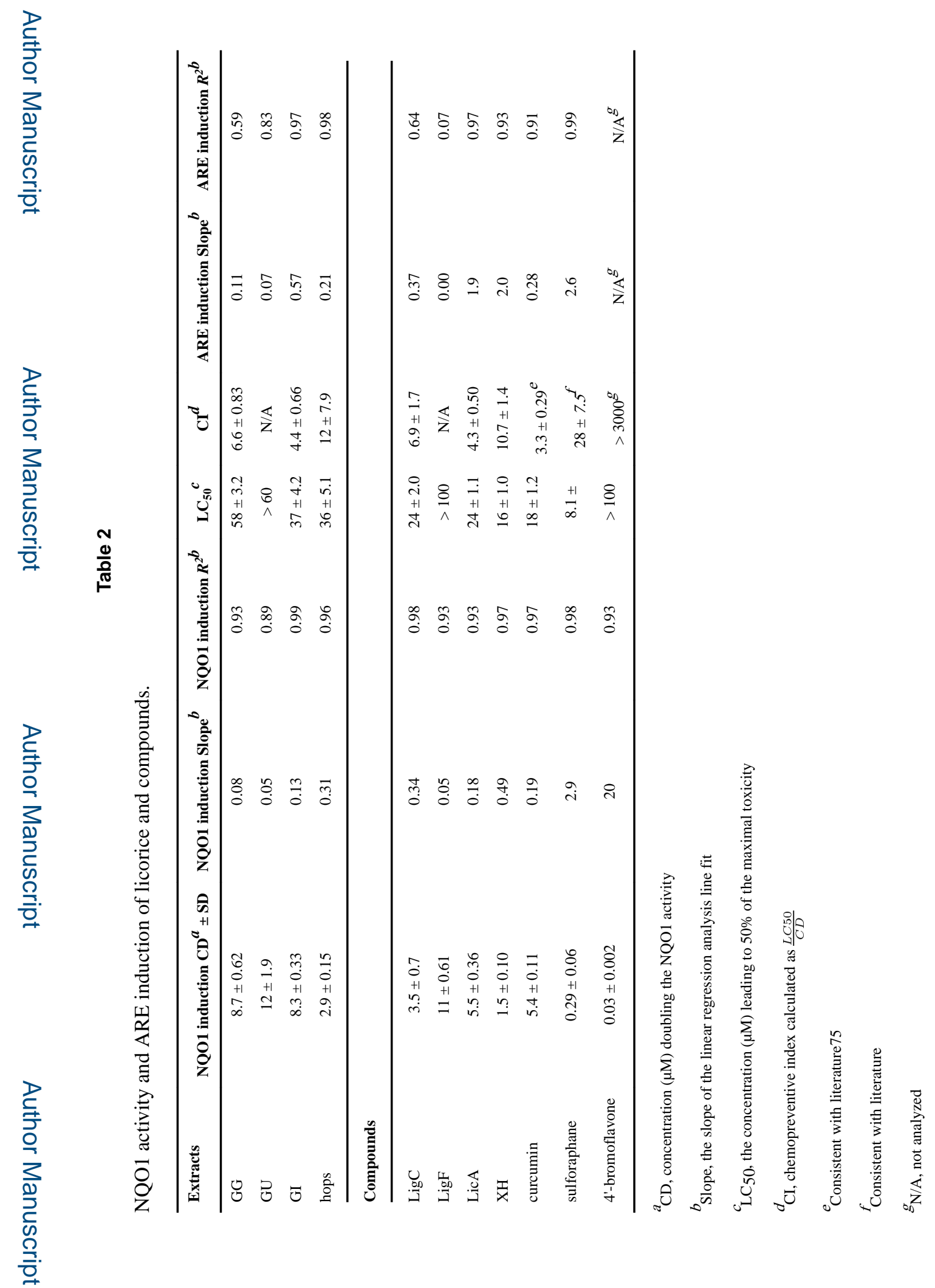

Chem Res Toxicol. Author manuscript; available in PMC 2016 November 16. 